\title{
中国鳞翅目新物种2020年度报告
}

戚慕杰๑, 孙浩๑, 左兴海 ${ }^{\circ}$ 李后魂 ${ }^{*}$

南开大学生命科学学院, 天津 300071

摘要: 本文总结了2020年国内外学者发表的中国鳞翅目新分类单元的情况。经过统计, 2020年中国共发表鳞翅目新分类群196 个, 其中新属 1 个, 新种 190 个, 新亚种 5 个; 发表国家级新记录 71 个; 发表新组合 55 个; 将 11 个名称处理为 9 个名称的异名; 新 种(亚种)分别隶属于 23 个科。海南和云南两省发表的新物种数明显高于其他地区，占全国新物种发表总数的 $2 / 5$; 新记录种发 表最多的地区为云南, 占全国新记录种总数的约 $1 / 2$ 。整体来看, 我国南方新物种和新记录种发表数量明显高于北方。

关键词: 鳞翅目; 新分类单元; 新组合; 新异名; 中国

戚慕杰, 孙浩, 左兴海, 李后魂 (2021) 中国鳞翅目新物种2020年度报告. 生物多样性, 29, 1035-1039. doi: 10.17520/biods.2021245.

Qi MJ, Sun H, Zuo XH, LI HH (2021) Annual report of new taxa for Chinese Lepidoptera in 2020. Biodiversity Science, 29, 1035-1039. doi: 10.17520/biods.2021245.

\section{Annual report of new taxa for Chinese Lepidoptera in 2020}

\author{
Mujie Qi ${ }^{(\mathbb{D}}$, Hao Sun ${ }^{\mathbb{D}}$, Xinghai Zuo ${ }^{\mathbb{1}}$, Houhun $\mathrm{Li}^{(\mathbb{D} *}$
}

College of Life Sciences, Nankai University, Tianjin 300071

\begin{abstract}
Aim: Lepidoptera is one of the largest orders in Insecta and is a group with high economic importance as many pest species of Lepidoptera occur all over the world. China is one of the most biodiverse countries in the world, as it ranges from the Palaearctic to Oriental Regions, and many species new to science are described each year. The aim of this study is to summarize the new taxa of Lepidoptera from China that were reported in 2020.

Methods: Information regarding new species, newly recorded species, and new synonyms and combinations were collected from several common journals of taxonomy and monographs. In total, 102 articles and 3 monographs are included in this report. From these sources, the scientific names, type localities, and the other relevant information have been summarized.

Results: The number of new taxa of Chinese Lepidoptera published by domestic and foreign researchers in 2020 has been summarized. In 2020, 196 new taxa of Lepidoptera were reported, including 1 new genus, 190 new species, 5 new subspecies, and 71 newly recorded species for China. Additionally, 55 new combinations and 11 new synonyms have been suggested. All of the new species and subspecies belong to 23 families.

Conclusions: The number of new species published in Hainan and Yunnan was significantly higher than that in other regions and accounted for two-fifths of the total number of new species published in China in 2020. Yunnan Province had the highest number of newly recorded species for a region in China and accounted for about half of the total number of newly recorded species in China. In general, the number of new species and newly recorded species collected in the south are significantly higher than those in north of China. Moreover, the discovery and description of all Lepidoptera species in China are far from completed, and further investigation of Lepidoptera in China is necessary.
\end{abstract}

Key words: Lepidoptera; new taxa; new combination; new synonyms; China

鳞翅目包括蛾类和蝴蝶, 估计有 50 万种, 目前 已记载近16万种(Kristensen et al, 2007), 是昆虫纲
中最大的目之一, 大约占全部生物种类的 $10 \%$, 分 布十分广泛。许多鳞翅目成虫具有传粉功能, 家蚕

收稿日期: 2021-06-21; 接受日期: 2021-08-03

基金项目: 国家自然科学基金(31872267; 31601883)

* 通讯作者 Author for correspondence. E-mail: lihouhun@nankai.edu.cn 
(Bombyx mori)、柞蚕(Antheraea pernyi)、天䖯(A. yamamai)等是著名的产丝昆虫, 种类繁多的蝴蝶和 蛾类具有较高的艺术观赏价值, 是重要的观赏资源 昆虫。此外, 鳞翅目还是农林害虫中种类最多的一 个目，危害农林作物、粮食、药材、干果、皮毛等 物品的咜存(袁峰等, 2005)。因鳞翅目昆虫绝大多数 种类的幼虫取食植物, 许多种类是农林业的害虫。 其中小蛾类作为害虫, 尤以蛙果、蛙梢、卷叶、食 叶、潜叶和造瘘者居多，常对农林业生产造成危害; 只有少数类群为捕食性, 是其他害虫的天敌。成虫 多有访花习性, 其传粉作用可以增加农林作物的产 量, 但它们大多在夜间活动, 不像膜翅目昆虫的访 花那样容易引起注意。因此, 鳞翅目昆虫具有很重 要的经济价值(李后魂等, 2012)。

我国鳞翅目昆虫分类学研究起步较晚, 基础薄 弱, 很多蛾类昆虫的分类在国内仍处于混乱的状态, 有大量的研究空白类群。我国幅员辽阔, 生物资源 丰富, 在世界动物区系和全球生物多样性研究中具 有举足轻重的作用。因此, 有必要按照一定年限, 对分散于各种书籍或刊物中的有关鳞翅目新分类 群、名称变化及新发现等进行总结, 从而方便昆虫 学相关研究人员参考和引用, 并对处理不当的类群 及时进行分类学整理。本文主要关注2020年中国鳞 翅目分类学研究进展, 包括国内外学者对中国鳞翅 目的分类研究以及我国学者对国外鳞翅目的研究 情况。

\section{1 方法}

本文系统检索了主要发表昆虫类群的期刊, 尤 其是鳞翅目发表较多的主流期刊, 同时, 通过Web of Science (http://www.webofscience.com)、中国知网 (http://www.cnki.net)等网站, 利用检索词 Lepidoptera、China、new、review、synonym等进行了补充 检索。

\section{2 结果}

\section{1 中国新发表物种的基本状况}

经过系统检索和整理, 2020年有19个国内外期 刊和专著的 81 篇论文涉及了鳞翅目新分类群(如: 新属、新种、新亚种)、新组合、新异名等。其中, 中 国鳞翅目昆虫新物种(含亚种)发表数量为 195 个, 包 括133个小蛾类(Microlepidoptera)新种、58个大蛾类
(Macrolepidoptera)新种(含亚种)、2个蝴蝶新种和 2 个蝴蝶新亚种。在现在已知的 48 个鳞翅目总科中, 小蛾类总科占了 $3 / 4$ 以上，在科级阶元上小蛾类占 鳞翅目总数的 $2 / 3$ 以上, 但属级只占到 $1 / 6$ 左右, 到 种一级比例则更低，除类群划分上的原因外，也从 一个侧面反映出研究的严重不足，因此，小蛾类有 更大的研究和提升空间。相应地, 其发表物种的数 量也明显多于大蛾类及蝶类。在2020年新发表的全 部小蛾类新物种中，种类最多的几个科为: 列蛾科 (55个)、织蛾科 (28个)、展足蛾科(15个)、蛆蛾科(14 个)、草螟科(11个)。大蛾类全部新种中，种类最多 的是目夜蛾科, 有 22 个, 蝶类蛱蝶科与弄蝶科新种 各 1 个，灰蝶科 2 个新亚种(表1)。

2020 年中国学者发表了其他 7 个国家的 32 个新 物种(含琥珀 1 种), 隶属于 5 科, 其中，涉及小蛾类 3

表1 中国鳞翅目2020年发表的新分类单元数量

Table 1 Number of new taxa of Chinese Lepidoptera published in 2020

\begin{tabular}{|c|c|c|c|c|}
\hline $\begin{array}{l}\text { 科 } \\
\text { Family }\end{array}$ & $\begin{array}{l}\text { 新属 } \\
\text { New } \\
\text { genus }\end{array}$ & $\begin{array}{l}\text { 新种 } \\
\text { New } \\
\text { species }\end{array}$ & $\begin{array}{l}\text { 新亚种 } \\
\text { New } \\
\text { subspecies }\end{array}$ & $\begin{array}{l}\text { 总数 } \\
\text { Total }\end{array}$ \\
\hline 羽蛾科 Alucitidae & 0 & 1 & 0 & 1 \\
\hline 列蛾科 Autostichidae & 0 & 55 & 0 & 55 \\
\hline 项蛾科 Bucculatricidae & 0 & 1 & 0 & 1 \\
\hline 草蛽科 Crambidae & 0 & 11 & 0 & 11 \\
\hline 草蛾科 Ethmiidae & 0 & 1 & 0 & 1 \\
\hline 目夜蛾科 Erebidae & 0 & 22 & 0 & 11 \\
\hline 麦蛾科 Gelechiidae & 0 & 2 & 0 & 2 \\
\hline 尺蛾科 Geometridae & 0 & 5 & 0 & 5 \\
\hline 弄蝶科 Hesperiidae & 0 & 1 & 0 & 1 \\
\hline 祝蛾科 Lecithoceridae & 0 & 3 & 0 & 3 \\
\hline 刺蛾科 Limacodidae & 1 & 6 & 0 & 7 \\
\hline 灰蝶科 Lycaenidae & 0 & 0 & 2 & 2 \\
\hline 小翅蛾科 Micropterigidae & 0 & 2 & 0 & 2 \\
\hline 夜蛾科 Noctuidae & 0 & 10 & 3 & 14 \\
\hline 瘤蛾科 Nolidae & 0 & 3 & 0 & 3 \\
\hline 蛱蝶科 Nymphalidae & 0 & 1 & 0 & 1 \\
\hline 织蛾科 Oecophoridae & 0 & 28 & 0 & 28 \\
\hline 蚯蛾科 Pyralidae & 0 & 14 & 0 & 14 \\
\hline 纤蛾科 Roeslerstammiidae & & 3 & 0 & 3 \\
\hline 天蛾科 Sphingidae & 0 & 1 & 0 & 1 \\
\hline 展足蛾科 Stathmopodidae & 0 & 15 & 0 & 15 \\
\hline 波纹蛾科 Thyatiridae & 0 & 2 & 0 & 2 \\
\hline 谷蛾科 Tineidae & 0 & 3 & 0 & 3 \\
\hline 合计 Total & 1 & 190 & 5 & 195 \\
\hline
\end{tabular}


科(麦蛾科 13 种、织蛾科 9 种和列蛾科 2 种), 大蛾类 2 科(目夜蛾科6种和尺蛾科1琥珀新种)。7个国家中, 越南的种类为 15 种, 老挝 5 种, 其余国家未超过 5 种 (表2)。

2020 年发表的全部 169 个新种中, 涉及 8 个新种 的8篇论文至少提供了线粒体基因COI数据, 占新 物种总数的 $4.7 \%$ 。这些包含分子系统学证据的新种 全部发表在期刊中, 特别是被SCI索引的期刊, 发 表在专著中的新种则没有包含分子证据。线粒体基 因组的COI基因是最早应用于鳞翅目昆虫的DNA条 形码基因, 同时也是目前鳞翅目中物种划分最常用 的基因。尽管如此, 2020年仅有不到5\%的鳞翅目新 种发表时提供至少 1 个分子数据, 绝大多数仍只依 据形态特征发表, 相信未来会有越来越多的作者选 择在鳞翅目新种发表时将 COI或其他基因序列作为 重要证据一同发表。

\section{2 新发表的属级分类群}

2020年中国鳞翅目昆虫发表了1个新属名, 即 爱刺蛾属(Epsteinius Lin, Braby \& Hsu, gen. nov.), 隶属于刺蛾科, 该属为单型属, 与纤刺蛾属 (Microleon)近似(Lin et al, 2020)。另外, 中国学者还 发表了一个化石新属, 隶属于尺蛾科, 该属为来自 中新世多米尼加琥珀的化石新属中新尺蛾属 (Miogeometrida Zhang, Shih \& Shih, gen. nov.) (Zhang WT et al, 2020)。

\section{3 新分类群所属的科级分类单元}

2020年, 中国学者参与发表的我国及其他国家 的鳞翅目新分类阶元(种及亚种)共计 223 个, 隶属于

表2 2020年中国学者发表的中国以外的鳞翅目新分类单元 Table 2 New taxa of foreign Lepidoptera published by Chinese researchers in 2020

\begin{tabular}{|c|c|c|c|}
\hline $\begin{array}{l}\text { 科 } \\
\text { Family }\end{array}$ & $\begin{array}{l}\text { 新属 } \\
\text { New genus }\end{array}$ & $\begin{array}{l}\text { 新种及国家 } \\
\text { New species \& Country }\end{array}$ & $\begin{array}{l}\text { 总数 } \\
\text { Total }\end{array}$ \\
\hline $\begin{array}{l}\text { 列蛾科 } \\
\text { Autostichidae }\end{array}$ & 0 & 2 (泰国 Thailand) & 2 \\
\hline $\begin{array}{l}\text { 目夜蛾科 } \\
\text { Erebidae }\end{array}$ & 0 & $\begin{array}{l}3 \text { (马来西亚 Malaysia)、1 (柬埔寨 } \\
\text { Cambodia)、2 (越南 Vietnam)、 } \\
1 \text { (缅甸 Myanmar) }\end{array}$ & 7 \\
\hline $\begin{array}{l}\text { 麦蛾科 } \\
\text { Gelechiidae }\end{array}$ & 0 & 13 (越南 Vietnam) & 13 \\
\hline $\begin{array}{l}\text { 尺蛾科 } \\
\text { Geometridae }\end{array}$ & 1 & 1 (多米尼加 Dominica) & 1 \\
\hline $\begin{array}{l}\text { 织蛾科 } \\
\text { Oecophoridae }\end{array}$ & 0 & $\begin{array}{l}5 \text { (老挝 Laos)、3 (马来西亚 } \\
\text { Malaysia)、1 (泰国 Thailand) }\end{array}$ & 9 \\
\hline 合计 Total & 1 & 32 & 32 \\
\hline
\end{tabular}

23科63属。大蛾类中, 仅目夜蛾科和夜蛾科发表了 超过 10 个新种，其余新种发表较多的科大多集中在 小蛾类中, 如: 列蛾科、织蛾科、展足蛾科、螟蛾 科、草蛽科等, 以上几个科发表新种数都超过了 10 种(表1)。2020年中国鳞翅目发表新分类单元情况具 体如下:

列蛾科发表的 55 个新种全部集中在模列蛾属 (Meleonoma), 主要分布于广西、四川、云南、贵州、 浙江、海南等地区, 其中, 模式产地为海南的种类 有22种(Wang \& Zhu, 2020a, b; Zhu et al, 2020)。

织蛾科发表的 28 个新种，除桔织蛾属 (Lasiochira)的1个种以外, 其余全部集中在锦织蛾 属(Promalactis), 分布于我国南方的各省, 如: 海 南、浙江、广东、广西、云南、贵州等地区(Wang \& Liu, 2020a, b, c; Yin \& Cai, 2020)。

目夜蛾科发表22个新种, 除2种外, 其余全部 集中在灯蛾亚科, 其中, 报道新种最多的是狄苔蛾 属(Diduga) (6种)和雅苔蛾属(Ammatho) (4种), 其余 各属均未超过3种, 主要分布于广东、重庆、云南、 海南、台湾等地区(Zhao \& Han, 2020; Bayarsaikhan et al, 2020; Huang et al, 2020; Volynkin \& Wu, 2020; Wu \& Kishida, 2020)。

展足蛾科 15 个新种主要集中在展足蛾属 (Stathmopoda) (13种), 分布于云南、福建、广西、 海南、贵州等地区(Wang et al, 2020)。

蛽蛾科共发表14个新种, 集中在斑螟亚科(3属 10种)和螟蛾亚科(2属4种), 分布于云南、贵州、西 藏、浙江、福建等地区，少数分布于北方，如天津、 宁夏等地(Yang \& Ren, 2020; Qi MJ \& Li, 2020)。其 中叉斑蟆属(Dusungwua)发表新种6种, 栗斑螟属 (Epicrocis)和长颚螟属(Peucela)分别发表3个新种 (Ren et al, 2020; Qi et al, 2020; Liu \& Li, 2020)。

草螟科发表 11 个新种, 集中在斑野蛽亚科和野 蛽亚科, 分别发表新种 7 种和 3 种, 主要分布在海 南、广西、江西等地区(Liu et al, 2020; Qi WD \& Li, 2020; Yang et al, 2020; Zhang DD et al, 2020)。

刺蛾科发表 6 个新种, 其中爱刺蛾属 4 种, 分布 于云南、福建和陕西(Wu, 2020; Lin et al, 2020)。

尺蛾科发表 5 个新种, 分别分布于湖南、广西、 陕西和四川(Cui et al, 2020; Cheng \& Jiang, 2020)。

另外, 还有部分类群2020年发表新物种数少于 5 个, 如: 谷蛾科 3 个、纤蛾科 3 个、祝蛾科 3 个。 


\section{4 新分类群和新记录物种的省级分布}

2020年发表的中国鳞翅目昆虫新物种、新记录 种等主要分布在我国南方地区, 其中, 云南有39个 新种, 海南38个, 浙江 17 个, 分别约占 2020 年鳞翅 目新物种总数(195种)的 $20.0 \% 、 19.4 \%$ 和 $8.7 \%$ 。2020 年, 共计发表中国新记录43种, 其中, 发表数量较 多的省份分别是云南(21个)、黑龙江(11个)和浙江(7 个), 另外, 海南和西藏的中国新记录种数量均在5 种以上(图1)。

\section{5 发表鳞翅目新分类群的学者组成}

2020 年新发表的 195 个种及种下阶元由 34 个中 外作者团队发表。这些作者团队中有中国学者 80 人, 国外学者 32 人。其中, 15 个中国作者团队发表了 154 个种及种下新分类群，17个中外合作团队发表了 20 个新分类群, 11 个国外团队发表了剩余的 21 个新分 类群。2020年发表鳞翅目物种数量较多的中国研究 团队是李后魂团队, 共发表了 127 个种级新分类群, 国外学者是Volynkin AV, 发表了14个大蛾类种级新 分类群。

\section{6 发表新组合、新异名等}

2020年中国鳞翅目昆虫发表了 55 个新组合, 分 别出现在列蛾科(49个)、蛽蛾科(2个)、目夜蛾科(1 个)、灰蝶科 (1个)和弄蝶科(2个)。其中, 列蛾科发表

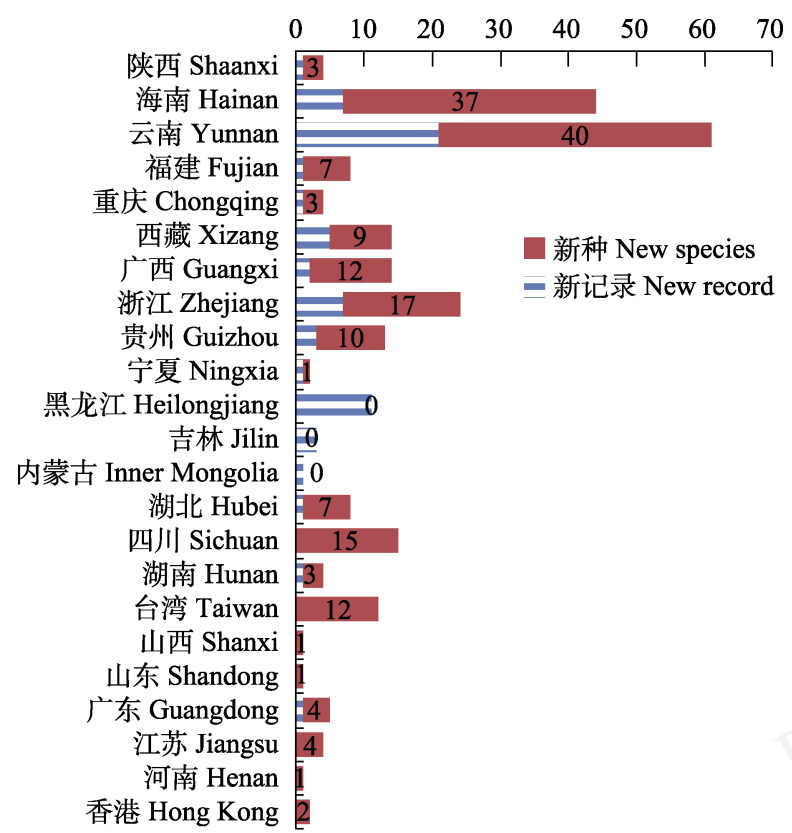

图12020年中国各省区发表的新分类群和国家级新记录物 种数量

Fig. 1 The provincial number of Chinese new taxa and newly recorded species published in 2020
的新组合占 2020 年度新组合总数的约 $5 / 6$ 。另外, 在 这55个新组合中, 有 2 个由国外作者发表, 2 个由 7 个 中外团队合作发表, 51 个由 2 个中国团队发表。王淑 霞(李后魂、王淑霞团队)发表了 49 个列蛾科新组合, 这 49 个名称转移均隶属于隐织蛾属(Cryptolechia), 其余 6 个名称转移涉及 6 个属。 2020 年有 11 个鳞翅目 物种名称被处理为 9 个名称的异名, 同时, 还有 1 个 蛱蝶科的属级名称被台湾学者和国外团队合作 (Wahlberg et al, 2020)处理为异名。以上具体分类学 处理详见附录 1 。

\section{3 小结}

2020年，我国鳞翅目分类学取得了一定成绩， 但是和我国总体昆虫多样性情况相比，分类工作依 然任重道远，很多类群依然有大量物种有待发现， 同时, 研究人员数量有限、部分地区调查基础较差、 大量分类阶元种类及分类地位混乱等情况依然严 峻。调查清楚我国鳞翅目本地状况依然需要相当长 的时间，另外，培养更多的鳞翅目分类学专业人才 也是非常必要的。

\section{ORCID}

戚慕杰 (D) https://orcid.org/0000-0002-1931-8401 孙浩 (D) https://orcid.org/0000-0002-6483-7606 左兴海 (D) https://orcid.org/0000-0002-4944-7175 李后魂 (D) https://orcid.org/0000-0002-8953-3422

\section{参考文献}

Bayarsaikhan U, Li HH, Im KH, Bae YS (2020) Four new and three newly recorded species of Diduga Moore, [1887] (Lepidoptera, Erebidae, Arctiinae) from China. Zootaxa, 4751, 357-368.

Cheng R, Jiang N (2020) Two new species of the genus Timandra Duponchel (Lepidoptera: Geometridae) from China. Entomotaxonomia, 42, 189-193.

Cui L, Xue DY, Jiang N (2020) Two new species of the tribe Rhodometrini Agenjo, 1951 from Sichuan, China (Lepidoptera: Geometridae). SHILAP Revista de Lepidopterología, 48, 167-173.

Huang SY, Volynkin AV, Wang M, Fan XL (2020) Three new species of the genus Ammatho Walker, 1855 from China and Indochina (Lepidoptera: Erebidae: Arctiinae: Lithosiini). Zootaxa, 4809, 582-592.

Kristensen NP, Scoble M, Karsholt O (2007) Lepidoptera phylogeny and systematics: The state of inventorying moth and butterfly diversity. Zootaxa, 1668, 699-747.

Li HH (2012) Microlepidoptera of Qinling Mountains (Insecta: Lepidoptera). Science Press, Beijing. (in Chinese) [李后魂 
(2012) 秦岭小蛾类. 科学出版社, 北京.]

Lin YC, Braby MF, Hsu YF (2020) A new genus and species of slug caterpillar (Lepidoptera: Limacodidae) from Taiwan. Zootaxa, 4809, 374-382.

Liu HX, Li HH (2020) Review of the genus Epicrocis Zeller, 1848 in China (Lepidoptera, Pyralidae), with descriptions of three new species. Zootaxa, 4834, 133-144.

Liu P, Qi MJ, Wang SX (2020) Four new species of the genus Agrotera Schrank, 1802 (Pyraloidea: Crambidae: Spilomelinae) from Hainan Island. Zootaxa, 4731, 556-564.

Qi MJ, Li HH (2020) Genus Vietnamodes Leraut, 2017 (Lepidoptera, Pyralidae) new to China, with description of a new species. Zootaxa, 4803, 190-196.

Qi MJ, Zuo XH, Li HH (2020) Taxonomic study of genus Peucela Ragonot, 1891 (Lepidoptera, Pyralidae) in China, with descriptions of three new species. ZooKeys, 976, 147-158.

Qi WD, Li HH (2020) Taxonomic study of the genus Pagyda Walker, 1859 (Lepidoptera: Crambidae: Pyraustinae) from China, with descriptions of two new species. Oriental Insects, 54, 16-40.

Ren YD, Yang LL, Liu HX, Li HH (2020) Taxonomic review of the genus Dusungwua Kemal, Kizildağ \& Koçak, 2020 (Lepidoptera: Pyralidae), with descriptions of six new species and propositions of synonyms. Zootaxa, 4894, 341-365.

Volynkin AV, Wu S (2020) A review of the subgenus Delineatia Volynkin \& Huang, 2019 of the genus Ammatho Walker, 1855, with descriptions of two new species from Taiwan and Vietnam (Lepidoptera, Erebidae, Arctiinae, Lithosiini). Zootaxa, 4801, 237-250.

Wang AL, Guan W, Wang SX (2020) Genus Stathmopoda Herrich-Schäffer, 1853 (Lepidoptera: Stathmopodidae) from China: Descriptions of thirteen new species. Zootaxa, 4838, 358-380.

Wang SX, Liu C (2020a) Taxonomic study of the genus Promalactis Meyrick, 1908 (Lepidoptera: Oecophoridae) VII. The cornigera species group, with descriptions of six new species. Zootaxa, 4718, 77-86.

Wang SX, Liu C (2020b) Taxonomic study of the genus Promalactis Meyrick, 1908 (Lepidoptera: Oecophoridae) VIII. The densimacularis species group, with descriptions of four new species. Zootaxa, 4748, 78-86.

Wang SX, Liu C (2020c) Taxonomic study of the genus Promalactis Meyrick, 1908 (Lepidoptera: Oecophoridae) IX. The maculosa species-group, with descriptions of eighteen new species. Zootaxa, 4890, 38-66.

Wang SX, Zhu XJ (2020a) Study of the genus Meleonoma
Meyrick, 1914 (Lepidoptera: Autostichidae) from China, with descriptions of fifteen new species. Zootaxa, 4838, 331-357.

Wang SX, Zhu XJ (2020b) Study of the genus Meleonoma Meyrick, 1914 (Lepidoptera: Autostichidae) from China, with descriptions of twenty-one new species (II). Zootaxa, 4881, 257-289.

Wu CS (2020) Four new species of Limacodidae from China (Lepidoptera: Zygaenoidea). Zoological Systematics, 45, 316-320.

Wu S, Kishida Y (2020) Descriptions of three new species of the Miltochrista generic complex in Taiwan (Lepidoptera: Erebidae: Arctiinae). Japan Heterocerists' Journal, 293, 450-456.

Yang LL, Ren YD (2020) A new species of Pima Hulst, 1888 from China (Lepidoptera, Pyralidae, Phycitinae), with a key to Holarctic species. ZooKeys, 975, 111-124.

Yang ZF, Ullah M, Landry JF, Miller SE, Rosati ME, Zhang YL (2020) Reassessment of the moth genus Bacotoma, with a new species from Hainan Island (Lepidoptera: Crambidae: Spilomelinae). Insect Systematics \& Evolution, 51, 384-407.

Yin AH, Cai YP (2020) One new species and one newly recorded species of the genus Lasiochira Meyrick, 1931 (Lepidoptera, Oecophoridae) from China. ZooKeys, 918, 143-150.

Yuan F, Zhang YL, Feng JN, Hua BZ (2006) Taxonomy of Hexapoda, 2nd edn. China Agriculture Press, Beijing. (in Chinese) [袁锋, 张雅林, 冯纪年, 花保祯 (2006) 昆虫分 类学 (第二版). 中国农业出版社, 北京.]

Zhang DD, Chen K, Xiang LB (2020) Revision of the genus Epiparbattia Caradja, 1925 (Lepidoptera, Crambidae, Pyraustinae), based on morphology and molecular data. ZooKeys, 960, 143-155.

Zhang WT, Shih CK, Shih YH, Ren D (2020) A new macrolepidopteran moth (Insecta, Lepidoptera, Geometridae) in Miocene Dominican amber. ZooKeys, 965, 73-84.

Zhao TT, Han HL (2020) Four new species of the genus Diduga Moore, [1887] (Lepidoptera, Erebidae, Arctiinae) from China and Malaysia. ZooKeys, 985, 127-141.

Zhu XJ, Cai B, Wang SX (2020) Genus Meleonoma Meyrick, 1914 (Lepidoptera, Autostichidae) from Hainan Island, China, with descriptions of sixteen new species. ZooKeys, 975, 125-157.

\section{附录 Supplementary Material}

\section{附录12020年中国鳞翅昆虫新分类群目录}

Appendix 1 Bibliography of new taxa for Chinese Lepidoptera in 2020

http://www.biodiversity-science.net/fileup/PDF/2021245-1.pdf 
戚慕杰, 孙浩, 左兴海, 李后魂 (2021) 中国鳞翅目新物种 2020 年度报告. 生物多样性, 29, 1035-1039.

http://www.biodiversity-science.net/CN/10.17520/biods.2021245

附录1 2020年中国鳞翅昆虫新分类群目录

Appendix 1 Bibliography of new taxa for Chinese Lepidoptera in 2020

\section{Alucitidae 羽蛾科}

Pterotopteryx taoa Ulf Buchsbaum, Mei-Yu Chen \& Ding-Jia Chen [New Species]

Ulf Buchsbaum, Mei-Yu Chen \& Ding-Jia Chen. Pterotopteryx taoa sp. nov. from Lanyu Island, Taiwan (Lepidoptera, Alucitidae) Contribution to the moths of Taiwan. Spixiana, 43(1): 137-145.

CHINA (Taiwan)

\section{Autostichidae 列蛾科}

Meleonoma acutata Wang \& Zhu [New Species]

Shuxia Wang, Xiaoju Zhu. Study of the genus Meleonoma Meyrick, 1914 (Lepidoptera: Autostichidae) from China, with descriptions of twenty-one new species (II). Zootaxa, 4881 (2): 257-289.

CHINA (Chongqing)

Meleonoma acutiuscula (Wang, 2004) [New Combination]

B.: Cryptolechia acutiuscula Wang

Shuxia Wang, Xiaoju Zhu, Baixue Zhao, Xiaofei Yang. Taxonomic review of the genus Meleonoma Meyrick (Lepidoptera: Autostichidae), with a checklist of all the described species. Zootaxa, 4763 (3): 371-393.

CHINA (Guizhou).

Meleonoma anisodonta Wang \& Zhu [New Species]

Shuxia Wang, Xiaoju Zhu. Study of the genus Meleonoma Meyrick, 1914 (Lepidoptera: Autostichidae) from China, with descriptions of fifteen new species. Zootaxa, 4838 (3): 331-357.

CHINA (Hainan)

Meleonoma annulignatha Wang \& Zhu [New Species]

Shuxia Wang, Xiaoju Zhu. Study of the genus Meleonoma Meyrick, 1914 (Lepidoptera: Autostichidae) from China, with descriptions of twenty-one new species (II). Zootaxa, 4881 (2): 257-289.

CHINA (Guangxi)

Meleonoma anthaedeaga (Wang, 2003) [New Combination]

B.: Cryptolechia anthaedeaga Wang

Shuxia Wang, Xiaoju Zhu, Baixue Zhao, Xiaofei Yang. Taxonomic review of the genus Meleonoma Meyrick (Lepidoptera: Autostichidae), with a checklist of all the described species. Zootaxa, 4763 (3): 371-393.

CHINA (Henan, Hubei, Zhejiang).

Meleonoma apicicurvata Wang [New Species]

Xiaoju Zhu, Bo Cai, Shuxia Wang. Genus Meleonoma Meyrick, 1914 (Lepidoptera, Autostichidae) from Hainan Island, China, with descriptions of sixteen new species. ZooKeys, 975: 125-157.

CHINA (Hainan)

Meleonoma apicirectangula Wang [New Species]

Xiaoju Zhu, Bo Cai, Shuxia Wang. Genus Meleonoma Meyrick, 1914 (Lepidoptera, Autostichidae) from Hainan Island, China, with descriptions of sixteen new species. ZooKeys 975: 125-157.

CHINA (Hainan)

Meleonoma argometra (Meyrick, 1935) [New Combination]

B.: Cryptolechia argometra Meyrick

Shuxia Wang, Xiaoju Zhu, Baixue Zhao, Xiaofei Yang. Taxonomic review of the genus Meleonoma Meyrick (Lepidoptera: Autostichidae), with a checklist of all the described species. Zootaxa, 4763(3): 371-393.

CHINA (Taiwan).

Meleonoma aridula Wang \& Zhu [New Record]

Shuxia Wang, Xiaoju Zhu. Study of the genus Meleonoma Meyrick, 1914 (Lepidoptera: Autostichidae) from China, with descriptions of fifteen new species. Zootaxa, 4838 (3): 331-357.

CHINA (Hainan)

Meleonoma artivalva Wang \& Zhu [New Species]

Shuxia Wang, Xiaoju Zhu. Study of the genus Meleonoma Meyrick, 1914 (Lepidoptera: Autostichidae) from China, with descriptions of twenty-one new species (II). Zootaxa, 4881 (2): 257-289.

CHINA (Fujian) 
Shuxia Wang, Xiaoju Zhu. Study of the genus Meleonoma Meyrick, 1914 (Lepidoptera: Autostichidae) from China, with descriptions of twenty-one new species (II). Zootaxa, 4881 (2): 257-289.

CHINA (Sichuan)

Meleonoma bicornea Wang \& Zhu [New Species]

Shuxia Wang, Xiaoju Zhu. Study of the genus Meleonoma Meyrick, 1914 (Lepidoptera: Autostichidae) from China, with descriptions of twenty-one new species (II). Zootaxa, 4881 (2): 257-289.

CHINA (Yunnan)

Meleonoma bicuspidata Wang [New Species]

Xiaoju Zhu, Bo Cai, Shuxia Wang. Genus Meleonoma Meyrick, 1914 (Lepidoptera, Autostichidae) from Hainan Island, China, with descriptions of sixteen new species. ZooKeys, 975: 125-157.

CHINA (Hainan)

Meleonoma bidentata Wang [New Species]

Xiaoju Zhu, Bo Cai, Shuxia Wang. Genus Meleonoma Meyrick, 1914 (Lepidoptera, Autostichidae) from Hainan Island, China, with descriptions of sixteen new species. ZooKeys, 975: 125-157.

CHINA (Hainan)

Meleonoma bidigitata Wang \& Zhu [New Species]

Shuxia Wang, Xiaoju Zhu. Study of the genus Meleonoma Meyrick, 1914 (Lepidoptera: Autostichidae) from China, with descriptions of twenty-one new species (II). Zootaxa, 4881 (2): 257-289.

CHINA (Jiangxi)

Meleonoma bifida (Wang, 2006) [New Combination]

B.: Cryptolechia bifida Wang

Shuxia Wang, Xiaoju Zhu, Baixue Zhao, Xiaofei Yang.. Taxonomic review of the genus Meleonoma Meyrick (Lepidoptera: Autostichidae), with a checklist of all the described species. Zootaxa, 4763 (3): 371-393.

CHINA (Guangxi)

Meleonoma bifoliolata (Wang, 2006) [New Combination]

B.: Cryptolechia bifoliolata Wang

Shuxia Wang, Xiaoju Zhu, Baixue Zhao, Xiaofei Yang. Taxonomic review of the genus Meleonoma Meyrick (Lepidoptera: Autostichidae), with a checklist of all the described species. Zootaxa, 4763 (3): 371-393.

CHINA (Fujian)

Meleonoma catenata Wang \& Zhu [New Species]

Shuxia Wang, Xiaoju Zhu. Study of the genus Meleonoma Meyrick, 1914 (Lepidoptera: Autostichidae) from China, with descriptions of fifteen new species. Zootaxa, 4838 (3): 331-357.

CHINA (Yunnan)

Meleonoma circinans Wang \& Zhu [New Species]

Shuxia Wang, Xiaoju Zhu. Study of the genus Meleonoma Meyrick, 1914 (Lepidoptera: Autostichidae) from China, with descriptions of twenty-one new species (II). Zootaxa, 4881 (2): 257-289.

CHINA (Yunnan)

Meleonoma compacta Wang \& Zhu [New Species]

Shuxia Wang, Xiaoju Zhu. Study of the genus Meleonoma Meyrick, 1914 (Lepidoptera: Autostichidae) from China, with descriptions of twenty-one new species (II). Zootaxa, 4881 (2): 257-289.

CHINA (Zhejiang)

Meleonoma concaviuscula (Wang, 2004) [New Combination]

B.: Cryptolechia concaviuscula Wang

Shuxia Wang, Xiaoju Zhu, Baixue Zhao, Xiaofei Yang. Taxonomic review of the genus Meleonoma Meyrick (Lepidoptera: Autostichidae), with a checklist of all the described species. Zootaxa, 4763 (3): 371-393.

CHINA (Guizhou).

Meleonoma concolora (Wang, 2006) [New Combination]

B.: Cryptolechia concolora Wang

Shuxia Wang, Xiaoju Zhu, Baixue Zhao, Xiaofei Yang. Taxonomic review of the genus Meleonoma Meyrick (Lepidoptera: Autostichidae), with a checklist of all the described species. Zootaxa, 4763 (3): 371-393.

CHINA (Henan)

Meleonoma conica Wang [New Species]

Xiaoju Zhu, Bo Cai, Shuxia Wang. Genus Meleonoma Meyrick, 1914 (Lepidoptera, Autostichidae) from Hainan Island, China, with descriptions of sixteen new species. ZooKeys 975: 125-157. 
戚慕杰, 孙浩, 左兴海, 李后魂 (2021) 中国鳞翅目新物种 2020 年度报告. 生物多样性, 29, 1035-1039.

http://www.biodiversity-science.net/CN/10.17520/biods.2021245

\section{CHINA (Hainan)}

Meleonoma cornutivalvata (Wang, 2003) [New Combination]

B.: Cryptolechia cornutivalvata Wang

Shuxia Wang, Xiaoju Zhu, Baixue Zhao, Xiaofei Yang. Taxonomic review of the genus Meleonoma Meyrick (Lepidoptera: Autostichidae), with a checklist of all the described species. Zootaxa, 4763 (3): 371-393.

CHINA (Guizhou, Jiangxi)

Meleonoma cuneata Wang \& Zhu [New Species]

Shuxia Wang, Xiaoju Zhu. Study of the genus Meleonoma Meyrick, 1914 (Lepidoptera: Autostichidae) from China, with descriptions of twenty-one new species (II). Zootaxa, 4881 (2): 257-289.

CHINA (Guizhou)

Meleonoma deflecta (Wang, 2003) [New Combination]

B.: Cryptolechia deflecta Wang.

Shuxia Wang, Xiaoju Zhu, Baixue Zhao, Xiaofei Yang. Taxonomic review of the genus Meleonoma Meyrick (Lepidoptera: Autostichidae), with a checklist of all the described species. Zootaxa, 4763 (3): 371-393.

CHINA (Gansu, Shaanxi)

Meleonoma denticulata (Wang, 2004) [New Combination]

B.: Cryptolechia denticulata Wang

Shuxia Wang, Xiaoju Zhu, Baixue Zhao, Xiaofei Yang. Taxonomic review of the genus Meleonoma Meyrick (Lepidoptera: Autostichidae), with a checklist of all the described species. Zootaxa, 4763 (3): 371-393.

CHINA (Guizhou).

Meleonoma dilativalva Wang \& Zhu [New Species]

Shuxia Wang, Xiaoju Zhu. Study of the genus Meleonoma Meyrick, 1914 (Lepidoptera: Autostichidae) from China, with descriptions of fifteen new species. Zootaxa, 4838 (3): 331-357.

CHINA (Yunnan)

Meleonoma dorsibacilliformis Wang \& Zhu [New Species]

Shuxia Wang, Xiaoju Zhu. Study of the genus Meleonoma Meyrick, 1914 (Lepidoptera: Autostichidae) from China, with descriptions of fifteen new species. Zootaxa, 4838 (3): 331-357.

CHINA (Guangxi)

Meleonoma dorsoprojecta (Wang, 2006) [New Combination]

B.: Cryptolechia dorsoprojecta Wang

Shuxia Wang, Xiaoju Zhu, Baixue Zhao, Xiaofei Yang. Taxonomic review of the genus Meleonoma Meyrick (Lepidoptera: Autostichidae), with a checklist of all the described species. Zootaxa, 4763 (3): 371-393.

CHINA (Fujian).

Meleonoma falsitorophanes (Wang, 2006) [New Combination]

B.: Cryptolechia falsitorophanes Wang

Shuxia Wang, Xiaoju Zhu, Baixue Zhao, Xiaofei Yang. Taxonomic review of the genus Meleonoma Meyrick (Lepidoptera: Autostichidae), with a checklist of all the described species. Zootaxa, 4763 (3): 371-393.

CHINA (Hubei).

Meleonoma falsivespertina (Wang, 2003) [New Combination]

B.: Cryptolechia falsivespertina Wang

Shuxia Wang, Xiaoju Zhu, Baixue Zhao, Xiaofei Yang. Taxonomic review of the genus Meleonoma Meyrick (Lepidoptera: Autostichidae), with a checklist of all the described species. Zootaxa, 4763 (3): 371-393.

CHINA (Hebei, Henan, Hubei, Shaanxi, Sichuan).

Meleonoma fasciculifera (Wang, 2004) [New Combination]

B.: Cryptolechia fasciculifera Wang

Shuxia Wang, Xiaoju Zhu, Baixue Zhao, Xiaofei Yang. Taxonomic review of the genus Meleonoma Meyrick (Lepidoptera: Autostichidae), with a checklist of all the described species. Zootaxa, 4763 (3): 371-393.

CHINA (Guizhou).

Meleonoma fascirupta (Wang, 2003) [New Combination]

B.: Cryptolechia fascirupta Wang

Shuxia Wang, Xiaoju Zhu, Baixue Zhao, Xiaofei Yang. Taxonomic review of the genus Meleonoma Meyrick (Lepidoptera: Autostichidae), with a checklist of all the described species. Zootaxa, 4763 (3): 371-393.

CHINA (Fujian, Guizhou, Sichuan). 
Meleonoma flavilineata Kitajima \& Sakamaki, 2019 [First time description of the female]

Shuxia Wang, Xiaoju Zhu. Study of the genus Meleonoma Meyrick, 1914 (Lepidoptera: Autostichidae) from China, with descriptions of twenty-one new species (II). Zootaxa, 4881 (2): 257-289.

CHINA (Chongqing, Guangdong, Guizhou, Zhejiang), Japan.

Meleonoma forcipata Wang \& Zhu [New Species]

Shuxia Wang, Xiaoju Zhu. Study of the genus Meleonoma Meyrick, 1914 (Lepidoptera: Autostichidae) from China, with descriptions of twenty-one new species (II). Zootaxa, 4881 (2): 257-289.

CHINA (Yunnan)

Meleonoma furcellata (Wang, 2004) [New Combination]

B.: Cryptolechia furcellata Wang

Shuxia Wang, Xiaoju Zhu, Baixue Zhao, Xiaofei Yang. Taxonomic review of the genus Meleonoma Meyrick (Lepidoptera: Autostichidae), with a checklist of all the described species. Zootaxa, 4763 (3): 371-393.

CHINA (Guizhou).

Meleonoma fustiformis (Wang, 2006) [New Combination]

B.: Cryptolechia fustiformis Wang

Shuxia Wang, Xiaoju Zhu, Baixue Zhao, Xiaofei Yang. Taxonomic review of the genus Meleonoma Meyrick (Lepidoptera: Autostichidae), with a checklist of all the described species. Zootaxa, 4763 (3): 371-393.

CHINA (Zhejiang).

Meleonoma gei (Wang, 2003) [New Combination]

B.: Cryptolechia gei Wang

Shuxia Wang, Xiaoju Zhu, Baixue Zhao, Xiaofei Yang. Taxonomic review of the genus Meleonoma Meyrick (Lepidoptera: Autostichidae), with a checklist of all the described species. Zootaxa, 4763 (3): 371-393.

CHINA (Guizhou, Sichuan).

Meleonoma hainanensis Wang [New Species]

Xiaoju Zhu, Bo Cai, Shuxia Wang. Genus Meleonoma Meyrick, 1914 (Lepidoptera, Autostichidae) from Hainan Island, China, with descriptions of sixteen new species. ZooKeys, 975: 125-157.

CHINA (Hainan)

Meleonoma hamatilis (Wang, 2004) [New Combination]

B.: Cryptolechia hamatilis Wang

Shuxia Wang, Xiaoju Zhu, Baixue Zhao, Xiaofei Yang. Taxonomic review of the genus Meleonoma Meyrick (Lepidoptera: Autostichidae), with a checklist of all the described species. Zootaxa, 4763 (3): 371-393.

CHINA (Guizhou).

Meleonoma infundibularis (Wang, 2006) [New Combination]

B.: Cryptolechia infundibularis Wang

Shuxia Wang, Xiaoju Zhu, Baixue Zhao, Xiaofei Yang. Taxonomic review of the genus Meleonoma Meyrick (Lepidoptera: Autostichidae), with a checklist of all the described species. Zootaxa, 4763 (3): 371-393.

CHINA (Guangxi).

Meleonoma jigongshanica (Wang, 2003) [New Combination]

B.: Cryptolechia jigongshanica Wang

Shuxia Wang, Xiaoju Zhu, Baixue Zhao, Xiaofei Yang. Taxonomic review of the genus Meleonoma Meyrick (Lepidoptera: Autostichidae), with a checklist of all the described species. Zootaxa, 4763 (3): 371-393.

CHINA (Henan, Hubei).

Meleonoma kangxianensis (Wang, 2003) [New Combination]

B.: Cryptolechia kangxianensis Wang

Shuxia Wang, Xiaoju Zhu, Baixue Zhao, Xiaofei Yang. Taxonomic review of the genus Meleonoma Meyrick (Lepidoptera: Autostichidae), with a checklist of all the described species. Zootaxa, 4763 (3): 371-393.

CHINA (Gansu).

Meleonoma lanceolata Wang \& Zhu [New Species]

Shuxia Wang, Xiaoju Zhu. Study of the genus Meleonoma Meyrick, 1914 (Lepidoptera: Autostichidae) from China, with descriptions of fifteen new species. Zootaxa, 4838 (3): 331-357.

CHINA (Zhejiang)

Meleonoma latifascia (Wang, 2004) [New Combination]

B.: Cryptolechia latifascia Wang

Shuxia Wang, Xiaoju Zhu, Baixue Zhao, Xiaofei Yang. Taxonomic review of the genus Meleonoma Meyrick (Lepidoptera: Autostichidae), with a checklist of all the described species. Zootaxa, 4763 (3): 371-393. 
戚慕杰, 孙浩, 左兴海, 李后魂 (2021) 中国鳞翅目新物种 2020 年度报告. 生物多样性, 29, 1035-1039.

http://www.biodiversity-science.net/CN/10.17520/biods.2021245

CHINA (Guizhou).

Meleonoma latiunca Wang [New Species]

Xiaoju Zhu, Bo Cai, Shuxia Wang. Genus Meleonoma Meyrick, 1914 (Lepidoptera, Autostichidae) from Hainan Island, China, with descriptions of sixteen new species. ZooKeys, 975: 125-157.

CHINA (Hainan)

Meleonoma ledongensis Wang \& Zhu [New Species]

Shuxia Wang, Xiaoju Zhu. Study of the genus Meleonoma Meyrick, 1914 (Lepidoptera: Autostichidae) from China, with descriptions of twenty-one new species (II). Zootaxa, 4881 (2): 257-289.

CHINA (Hainan)

Meleonoma leishana (Wang, 2006) [New Combination]

B.: Cryptolechia leishana Wang

Shuxia Wang, Xiaoju Zhu, Baixue Zhao, Xiaofei Yang. Taxonomic review of the genus Meleonoma Meyrick (Lepidoptera: Autostichidae), with a checklist of all the described species. Zootaxa, 4763 (3): 371-393.

CHINA (Guizhou).

Meleonoma linearis Wang [New Species]

Xiaoju Zhu, Bo Cai, Shuxia Wang. Genus Meleonoma Meyrick, 1914 (Lepidoptera, Autostichidae) from Hainan Island, China, with descriptions of sixteen new species. ZooKeys, 975: 125-157.

CHINA (Hainan)

Meleonoma liui (Wang, 2006) [New Combination]

B.: Cryptolechia liui Wang

Shuxia Wang, Xiaoju Zhu, Baixue Zhao, Xiaofei Yang. Taxonomic review of the genus Meleonoma Meyrick (Lepidoptera: Autostichidae), with a checklist of all the described species. Zootaxa, 4763 (3): 371-393.

CHINA (Gansu).

Meleonoma longaedeaga Wang \& Zhu [New Species]

Shuxia Wang, Xiaoju Zhu. Study of the genus Meleonoma Meyrick, 1914 (Lepidoptera: Autostichidae) from China, with descriptions of fifteen new species. Zootaxa, 4838 (3): 331-357.

CHINA (Hainan)

Meleonoma longihamata Wang \& Zhu [New Species]

Shuxia Wang, Xiaoju Zhu. Study of the genus Meleonoma Meyrick, 1914 (Lepidoptera: Autostichidae) from China, with descriptions of twenty-one new species (II). Zootaxa, 4881 (2): 257-289.

CHINA (Zhejiang)

Meleonoma longiprocessa Wang \& Zhu [New Species]

Shuxia Wang, Xiaoju Zhu. Study of the genus Meleonoma Meyrick, 1914 (Lepidoptera: Autostichidae) from China, with descriptions of fifteen new species. Zootaxa, 4838 (3): 331-357.

CHINA (Guizhou)

Meleonoma luniformis (Wang, 2006) [New Combination]

B.: Cryptolechia luniformis Wang

Shuxia Wang, Xiaoju Zhu, Baixue Zhao, Xiaofei Yang. Taxonomic review of the genus Meleonoma Meyrick (Lepidoptera: Autostichidae), with a checklist of all the described species. Zootaxa, 4763 (3): 371-393.

CHINA (Guangdong, Guangxi).

Meleonoma lunulata Wang \& Zhu [New Species]

Shuxia Wang, Xiaoju Zhu. Study of the genus Meleonoma Meyrick, 1914 (Lepidoptera: Autostichidae) from China, with descriptions of fifteen new species. Zootaxa, 4838 (3): 331-357.

CHINA (Fujian)

Meleonoma magnidentata Wang [New Species]

Xiaoju Zhu, Bo Cai, Shuxia Wang. Genus Meleonoma Meyrick, 1914 (Lepidoptera, Autostichidae) from Hainan Island, China, with descriptions of sixteen new species. ZooKeys, 975: 125-157.

CHINA (Hainan)

Meleonoma mecobursoides Wang \& Zhu [New Species]

Shuxia Wang, Xiaoju Zhu. Study of the genus Meleonoma Meyrick, 1914 (Lepidoptera: Autostichidae) from China, with descriptions of twenty-one new species (II). Zootaxa, 4881 (2): 257-289.

CHINA (Zhejiang)

Meleonoma menglana (Wang, 2006) [New Combination] 
B.: Cryptolechia menglana Wang

Shuxia Wang, Xiaoju Zhu, Baixue Zhao, Xiaofei Yang. Taxonomic review of the genus Meleonoma Meyrick (Lepidoptera: Autostichidae), with a checklist of all the described species. Zootaxa, 4763 (3): 371-393.

CHINA (Yunnan).

Meleonoma microbyrsa (Wang, 2003) [New Combination] [First time description of the female]

B.: Cryptolechia microbyrsa Wang

Shuxia Wang, Xiaoju Zhu, Baixue Zhao, Xiaofei Yang. Taxonomic review of the genus Meleonoma Meyrick (Lepidoptera: Autostichidae), with a checklist of all the described species. Zootaxa, 4763 (3): 371-393.

CHINA (Hainan, Henan).

Meleonoma microdonta Wang \& Zhu [New Species]

Shuxia Wang, Xiaoju Zhu. Study of the genus Meleonoma Meyrick, 1914 (Lepidoptera: Autostichidae) from China, with descriptions of twenty-one new species (II). Zootaxa, 4881 (2): 257-289.

CHINA (Zhejiang)

Meleonoma mirabilis (Wang, 2003) [New Combination]

B.: Cryptolechia mirabilis Wang

Shuxia Wang, Xiaoju Zhu, Baixue Zhao, Xiaofei Yang. Taxonomic review of the genus Meleonoma Meyrick (Lepidoptera: Autostichidae), with a checklist of all the described species. Zootaxa, 4763 (3): 371-393.

CHINA (Guizhou, Henan, Hunan, Jiangxi, Zhejiang).

Meleonoma muscosa (Wang, 2004) [New Combination]

B.: Cryptolechia muscosa Wang

Shuxia Wang, Xiaoju Zhu, Baixue Zhao, Xiaofei Yang. Taxonomic review of the genus Meleonoma Meyrick (Lepidoptera: Autostichidae), with a checklist of all the described species. Zootaxa, 4763 (3): 371-393.

CHINA (Guizhou).

Meleonoma neargometra (Wang, 2003) [New Combination]

B.: Cryptolechia neargometra Wang

Shuxia Wang, Xiaoju Zhu, Baixue Zhao, Xiaofei Yang. Taxonomic review of the genus Meleonoma Meyrick (Lepidoptera: Autostichidae), with a checklist of all the described species. Zootaxa, 4763 (3): 371-393.

CHINA (Gansu, Shaanxi).

Meleonoma olivaria (Wang, 2006) [New Combination]

B.: Cryptolechia olivaria Wang

Shuxia Wang, Xiaoju Zhu, Baixue Zhao, Xiaofei Yang. Taxonomic review of the genus Meleonoma Meyrick (Lepidoptera: Autostichidae), with a checklist of all the described species. Zootaxa, 4763 (3): 371-393.

CHINA (Zhejiang).

Meleonoma ornithorrhyncha Wang [New Species]

Xiaoju Zhu, Bo Cai, Shuxia Wang Genus Meleonoma Meyrick, 1914 (Lepidoptera, Autostichidae) from Hainan Island, China, with descriptions of sixteen new species. ZooKeys, 975: 125-157.

CHINA (Hainan)

Meleonoma papillata Wang \& Zhu [New Species]

Shuxia Wang, Xiaoju Zhu. Study of the genus Meleonoma Meyrick, 1914 (Lepidoptera: Autostichidae) from China, with descriptions of fifteen new species. Zootaxa, 4838 (3): 331-357.

CHINA (Yunnan)

Meleonoma papillisetosa Wang \& Zhu [New Species]

Shuxia Wang, Xiaoju Zhu. Study of the genus Meleonoma Meyrick, 1914 (Lepidoptera: Autostichidae) from China, with descriptions of twenty-one new species (II). Zootaxa, 4881 (2): 257-289.

CHINA (Guizhou)

Meleonoma parallela Wang \& Zhu [New Species]

Shuxia Wang, Xiaoju Zhu. Study of the genus Meleonoma Meyrick, 1914 (Lepidoptera: Autostichidae) from China, with descriptions of twenty-one new species (II). Zootaxa, 4881 (2): 257-289.

CHINA (Guizhou)

Meleonoma paranthaedeaga (Wang, 2003) [New Combination]

B.: Cryptolechia paranthaedeaga Wang

Shuxia Wang, Xiaoju Zhu, Baixue Zhao, Xiaofei Yang. Taxonomic review of the genus Meleonoma Meyrick (Lepidoptera: Autostichidae), with a checklist of all the described species. Zootaxa, 4763 (3): 371-393.

CHINA (Guizhou, Jiangxi, Zhejiang). 
Meleonoma parilis Wang [New Species]

Xiaoju Zhu, Bo Cai, Shuxia Wang. Genus Meleonoma Meyrick, 1914 (Lepidoptera, Autostichidae) from Hainan Island, China, with descriptions of sixteen new species. ZooKeys, 975: 125-157.

CHINA (Hainan)

Meleonoma parvissima Wang \& Zhu [New Species]

Shuxia Wang, Xiaoju Zhu. Study of the genus Meleonoma Meyrick, 1914 (Lepidoptera: Autostichidae) from China, with descriptions of fifteen new species. Zootaxa, 4838 (3): 331-357.

CHINA (Yunnan)

Meleonoma pectinalis Wang [New Species]

Xiaoju Zhu, Bo Cai, Shuxia Wang. Genus Meleonoma Meyrick, 1914 (Lepidoptera, Autostichidae) from Hainan Island, China, with descriptions of sixteen new species. ZooKeys, 975: 125-157.

CHINA (Hainan)

Meleonoma plicata Yin, Zhi, \& Cai [New Species]

Aihui Yin, Yan Zhi, Yanpeng Cai. Three new species of Meleonoma Meyrick from Yunnan, China (Lepidoptera, Gelechioidea, Xyloryctidae). ZooKeys, 904: 23-33.

CHINA (Yunnan)

Meleonoma proximideflecta (Wang, 2004) [New Combination]

B.: Cryptolechia proximideflecta Wang

Shuxia Wang, Xiaoju Zhu, Baixue Zhao, Xiaofei Yang. Taxonomic review of the genus Meleonoma Meyrick (Lepidoptera: Autostichidae), with a checklist of all the described species. Zootaxa, 4763 (3): 371-393.

CHINA (Guizhou).

Meleonoma proximihamatilis (Wang, 2006) [New Combination]

B.: Cryptolechia promixihamatilis Wang

Shuxia Wang, Xiaoju Zhu, Baixue Zhao, Xiaofei Yang. Taxonomic review of the genus Meleonoma Meyrick (Lepidoptera: Autostichidae), with a checklist of all the described species. Zootaxa, 4763 (3): 371-393.

CHINA (Sichuan).

Meleonoma puncticulata Wang [New Species]

Xiaoju Zhu, Bo Cai, Shuxia Wang. Genus Meleonoma Meyrick, 1914 (Lepidoptera, Autostichidae) from Hainan Island, China, with descriptions of sixteen new species. ZooKeys, 975: 125-157.

CHINA (Hainan)

Meleonoma quadritaeniata Wang [New Species]

Xiaoju Zhu, Bo Cai, Shuxia Wang. Genus Meleonoma Meyrick, 1914 (Lepidoptera, Autostichidae) from Hainan Island, China, with descriptions of sixteen new species. ZooKeys, 975: 125-157.

CHINA (Hainan)

Meleonoma recticostata Wang \& Zhu [New Species]

Shuxia Wang, Xiaoju Zhu. Study of the genus Meleonoma Meyrick, 1914 (Lepidoptera: Autostichidae) from China, with descriptions of twenty-one new species (II). Zootaxa, 4881 (2): 257-289.

CHINA (Hainan)

Meleonoma rectimarginalis (Wang, 2006) [New Combination]

B.: Cryptolechia rectimarginalis Wang

Shuxia Wang, Xiaoju Zhu, Baixue Zhao, Xiaofei Yang. Taxonomic review of the genus Meleonoma Meyrick (Lepidoptera: Autostichidae), with a checklist of all the described species. Zootaxa, 4763 (3): 371-393.

CHINA (Yunnan).

Meleonoma robusta (Wang, 2006) [New Combination]

B.: Cryptolechia robusta Wang

Shuxia Wang, Xiaoju Zhu, Baixue Zhao, Xiaofei Yang. Taxonomic review of the genus Meleonoma Meyrick (Lepidoptera: Autostichidae), with a checklist of all the described species. Zootaxa, 4763 (3): 371-393.

CHINA (Hubei).

Meleonoma robustispina Wang [New Species]

Xiaoju Zhu, Bo Cai, Shuxia Wang. Genus Meleonoma Meyrick, 1914 (Lepidoptera, Autostichidae) from Hainan Island, China, with descriptions of sixteen new species. ZooKeys, 975: 125-157.

CHINA (Hainan)

Meleonoma rostellata Wang [New Species]

Xiaoju Zhu, Bo Cai, Shuxia Wang. Genus Meleonoma Meyrick, 1914 (Lepidoptera, Autostichidae) from Hainan Island, China, with 
descriptions of sixteen new species. ZooKeys, 975: 125-157.

CHINA (Hainan)

Meleonoma rostriformis (Wang, 2006) [New Combination]

B.: Cryptolechia rostriformis Wang

Shuxia Wang, Xiaoju Zhu, Baixue Zhao, Xiaofei Yang. Taxonomic review of the genus Meleonoma Meyrick (Lepidoptera: Autostichidae), with a checklist of all the described species. Zootaxa, 4763 (3): 371-393.

CHINA (Fujian).

Meleonoma rugulosa Wang \& Zhu [New Species]

Shuxia Wang, Xiaoju Zhu. Study of the genus Meleonoma Meyrick, 1914 (Lepidoptera: Autostichidae) from China, with descriptions of fifteen new species. Zootaxa, 4838 (3): 331-357.

CHINA (Hainan)

Meleonoma scalprata Yin, Zhi, \& Cai [New Species]

Aihui Yin, Yan Zhi, Yanpeng Cai. Three new species of Meleonoma Meyrick from Yunnan, China (Lepidoptera, Gelechioidea, Xyloryctidae). ZooKeys, 904: 23-33.

CHINA (Yunnan)

Meleonoma segregnatha Wang \& Zhu [New Species]

Shuxia Wang, Xiaoju Zhu. Study of the genus Meleonoma Meyrick, 1914 (Lepidoptera: Autostichidae) from China, with descriptions of twenty-one new species (II). Zootaxa, 4881 (2): 257-289.

CHINA (Zhejiang)

Meleonoma similifloralis (Wang, 2006) [New Combination]

B.: Cryptolechia similifloralis Wang

Shuxia Wang, Xiaoju Zhu, Baixue Zhao, Xiaofei Yang. Taxonomic review of the genus Meleonoma Meyrick (Lepidoptera: Autostichidae), with a checklist of all the described species. Zootaxa, 4763 (3): 371-393.

CHINA (Hubei, Sichuan)

Meleonoma sinuicosta Wang \& Zhu [New Species]

Shuxia Wang, Xiaoju Zhu. Study of the genus Meleonoma Meyrick, 1914 (Lepidoptera: Autostichidae) from China, with descriptions of twenty-one new species (II). Zootaxa, 4881 (2): 257-289.

CHINA (Guangxi)

Meleonoma solifasciaria (Wang, 2004) [New Combination]

B.: Cryptolechia solifasciaria Wang

Shuxia Wang, Xiaoju Zhu, Baixue Zhao, Xiaofei Yang. Taxonomic review of the genus Meleonoma Meyrick (Lepidoptera: Autostichidae), with a checklist of all the described species. Zootaxa, 4763 (3): 371-393.

CHINA (Guizhou).

Meleonoma spinifera (Wang, 2004) [New Combination]

B.: Cryptolechia spinifera Wang

Shuxia Wang, Xiaoju Zhu, Baixue Zhao, Xiaofei Yang. Taxonomic review of the genus Meleonoma Meyrick (Lepidoptera: Autostichidae), with a checklist of all the described species. Zootaxa, 4763 (3): 371-393.

CHINA (Guizhou).

Meleonoma sticta (Wang, 2006) [New Combination]

B.: Cryptolechia sticta Wang

Shuxia Wang, Xiaoju Zhu, Baixue Zhao, Xiaofei Yang. Taxonomic review of the genus Meleonoma Meyrick (Lepidoptera: Autostichidae), with a checklist of all the described species. Zootaxa, 4763 (3): 371-393.

CHINA (Sichuan).

Meleonoma stictifascia (Wang, 2003) [New Combination]

B.: Cryptolechia stictifascia Wang

Shuxia Wang, Xiaoju Zhu, Baixue Zhao, Xiaofei Yang. Taxonomic review of the genus Meleonoma Meyrick (Lepidoptera: Autostichidae), with a checklist of all the described species. Zootaxa, 4763 (3): 371-393.

CHINA (Fujian, Guizhou, Henan, Shaanxi).

Meleonoma taeniata Yin, Zhi, \& Cai [New Species]

Aihui Yin, Yan Zhi, Yanpeng Cai. Three new species of Meleonoma Meyrick from Yunnan, China (Lepidoptera, Gelechioidea, Xyloryctidae). ZooKeys, 904: 23-33.

CHINA (Yunnan)

Meleonoma taiwanensis Wang \& Zhu [New Species]

Shuxia Wang, Xiaoju Zhu. Study of the genus Meleonoma Meyrick, 1914 (Lepidoptera: Autostichidae) from China, with descriptions 
of twenty-one new species (II). Zootaxa, 4881 (2): 257-289.

CHINA (Taiwan)

Meleonoma taeniophylla Wang \& Zhu [New Species]

Shuxia Wang, Xiaoju Zhu. Study of the genus Meleonoma Meyrick, 1914 (Lepidoptera: Autostichidae) from China, with descriptions of twenty-one new species (II). Zootaxa, 4881 (2): 257-289.

CHINA (Yunnan)

Meleonoma tenuiuncata Wang \& Zhu [New Species]

Shuxia Wang, Xiaoju Zhu. Study of the genus Meleonoma Meyrick, 1914 (Lepidoptera: Autostichidae) from China, with descriptions of fifteen new species. Zootaxa, 4838 (3): 331-357.

CHINA (Guangxi)

Meleonoma tianmushana Wang \& Zhu [New Species]

Shuxia Wang, Xiaoju Zhu. Study of the genus Meleonoma Meyrick, 1914 (Lepidoptera: Autostichidae) from China, with descriptions of fifteen new species. Zootaxa, 4838 (3): 331-357.

CHINA (Zhejiang)

Meleonoma triacantha Wang \& Zhu [New Species]

Shuxia Wang, Xiaoju Zhu. Study of the genus Meleonoma Meyrick, 1914 (Lepidoptera: Autostichidae) from China, with descriptions of fifteen new species. Zootaxa, 4838 (3): 331-357.

CHINA (Guangxi)

Meleonoma trimaculata (Wang, 2006) [New Combination]

B.: Cryptolechia trimaculata Wang

Shuxia Wang, Xiaoju Zhu, Baixue Zhao, Xiaofei Yang. Taxonomic review of the genus Meleonoma Meyrick (Lepidoptera: Autostichidae), with a checklist of all the described species. Zootaxa, 4763 (3): 371-393.

CHINA (Fujian)

Meleonoma varifascirupta (Wang, 2003) [New Combination]

B.: Cryptolechia varifascirupta Wang

Shuxia Wang, Xiaoju Zhu, Baixue Zhao, Xiaofei Yang. Taxonomic review of the genus Meleonoma Meyrick (Lepidoptera: Autostichidae), with a checklist of all the described species. Zootaxa, 4763 (3): 371-393.

CHINA (Guizhou, Sichuan)

Meleonoma ventrospinosa Wang \& Zhu [New Species]

Shuxia Wang, Xiaoju Zhu. Study of the genus Meleonoma Meyrick, 1914 (Lepidoptera: Autostichidae) from China, with descriptions of fifteen new species. Zootaxa, 4838 (3): 331-357.

CHINA (Hubei)

Meleonoma vespertina (Meyrick, 1910) [New Combination]

B.: Cryptolechia vespertina Meyrick

Shuxia Wang, Xiaoju Zhu, Baixue Zhao, Xiaofei Yang. Taxonomic review of the genus Meleonoma Meyrick (Lepidoptera: Autostichidae), with a checklist of all the described species. Zootaxa, 4763 (3): 371-393.

CHINA (Fujian, Sichuan, Taiwan, Zhejiang), India.

Meleonoma wenxianica (Wang, 2006) [New Combination]

B.: Cryptolechia wenxianica Wang,

Shuxia Wang, Xiaoju Zhu, Baixue Zhao, Xiaofei Yang. Taxonomic review of the genus Meleonoma Meyrick (Lepidoptera: Autostichidae), with a checklist of all the described species. Zootaxa, 4763 (3): 371-393.

CHINA (Gansu).

Meleonoma zeloxantha (Meyrick, 1934) [New Combination]

B.: Cryptolechia zeloxantha Meyrick,

Shuxia Wang, Xiaoju Zhu, Baixue Zhao, Xiaofei Yang. Taxonomic review of the genus Meleonoma Meyrick (Lepidoptera: Autostichidae), with a checklist of all the described species. Zootaxa, 4763 (3): 371-393.

CHINA (Guizhou, Sichuan).

Meleonoma zhengi (Wang, 2003) [New Combination]

B.: Cryptolechia zhengi Wang

Shuxia Wang, Xiaoju Zhu, Baixue Zhao, Xiaofei Yang. Taxonomic review of the genus Meleonoma Meyrick (Lepidoptera: Autostichidae), with a checklist of all the described species. Zootaxa, 4763 (3): 371-393.

CHINA (Gansu, Henan, Shaanxi). 
Bucculatrix duanwuia Liu [New Species]

Encui Wang, Wei Li, Tengteng Liu. Bucculatricidae associated with Asteraceae in China, with one new species (Lepidoptera: Gracillarioidea). Zootaxa, 4766 1: 181-191.

CHINA (Shandong)

Bucculatrix notella Seksjaeva, 1996 [New Record]

Encui Wang, Wei Li, Tengteng Liu. Bucculatricidae associated with Asteraceae in China, with one new species (Lepidoptera: Gracillarioidea). Zootaxa, 4766 1: 181-191.

CHINA (Shaanxi)

\section{Crambidae 草蛽科}

Agrotera aculeata Liu, Qi \& Wang [New Species]

Ping Liu, Mujie Qi \& Shuxia Wang. Four new species of the genus Agrotera Schrank, 1802

(Pyraloidea: Crambidae: Spilomelinae) from Hainan Island. Zootaxa, 4731 (4): 556-564.

CHINA (Hainan)

Agrotera dentata Liu, Qi \& Wang [New Species]

Ping Liu, Mujie Qi \& Shuxia Wang. Four new species of the genus Agrotera Schrank, 1802

(Pyraloidea: Crambidae: Spilomelinae) from Hainan Island. Zootaxa, 4731 (4): 556-564.

CHINA (Hainan)

Agrotera protensa Liu, Qi \& Wang [New Species]

Ping Liu, Mujie Qi \& Shuxia Wang. Four new species of the genus Agrotera Schrank, 1802

(Pyraloidea: Crambidae: Spilomelinae) from Hainan Island. Zootaxa, 4731 (4): 556-564.

CHINA (Hainan)

Agrotera robustispina Liu, Qi \& Wang [New Species]

Ping Liu, Mujie Qi \& Shuxia Wang. Four new species of the genus Agrotera Schrank, 1802

(Pyraloidea: Crambidae: Spilomelinae) from Hainan Island. Zootaxa, 4731 (4): 556-564.

CHINA (Hainan)

Bacotoma hainanensis Yang, Ullaha, Jean-François Landryb, Scott E. Millerc, Margaret E. Rosatic \& Zhang [New Species]

Zhaofu Yang, Misbah Ullah, Jean-François Landryb, Scott E. Millerc, Margaret E. Rosatic, Yalin Zhang. Reassessment of the moth genus Bacotoma, with a new species from Hainan Island Lepidoptera: Crambidae: Spilomelinae). Insect Systematics \& Evolution, 51 (3): 384-407

CHINA (Hainan)

Epiparbattia multispinalis Zhang \& Chen [New Species]

Dandan Zhang, Kai Chen, Lanbin XiangRevision of the genus Epiparbattia Caradja, 1925 (Lepidoptera, Crambidae, Pyraustinae), based on morphology and molecular data. ZooKeys, 960: 143-155.

CHINA (Hubei)

Metaeuchromius grandispinata Li [New Species]

Yang Jingbo, Liu Wei, Li Weichun. Geographical distribution patterns of Metaeuchromius in Asia and description of a new species from China (Lepidoptera, Crambidae). Journal of Asia-Pacific Entomology, 23(3): 845-851.

CHINA (Jiangxi)

Nagiella bispina Lu \& Du [New Species]

Xiao-Qiang Lu, Xi-Cui Du. Revision of Nagiella Munroe (Lepidoptera, Crambidae), with the description of a new species from China. ZooKeys, 964: 143-159.

CHINA (Yunnan)

Nagiella hortulatoides Munroe [New Record]

Xiao-Qiang Lu, Xi-Cui Du. Revision of Nagiella Munroe (Lepidoptera, Crambidae), with the description of a new species from China. ZooKeys, 964: 143-159.

CHINA (Yunnan)

Pagyda recticlavata $\mathrm{Li}$ [New Species]

Wanding Qi, Houhun Li. Taxonomic study of the genus Pagyda Walker, 1859 (Lepidoptera: Crambidae: Pyraustinae) from China, with descriptions of two new species. Oriental Insects, 54(1): 16-40.

CHINA (Guangxi)

Pagyda parallelivalva Li [New Species]

Wanding Qi, Houhun Li. Taxonomic study of the genus Pagyda Walker, 1859 (Lepidoptera: Crambidae: Pyraustinae) from China, with descriptions of two new species. Oriental Insects, 54(1): 16-40. 
戚慕杰, 孙浩, 左兴海, 李后魂 (2021) 中国鳞翅目新物种 2020 年度报告. 生物多样性, 29, 1035-1039.

http://www.biodiversity-science.net/CN/10.17520/biods.2021245

\section{CHINA (Hainan)}

Platamonina Shaffer \& Munroe, 2007 [New Synonyms]

S.: Bacotoma Moore

Zhaofu Yang, Misbah Ullah, Jean-François Landryb, Scott E. Millerc, Margaret E. Rosatic, Yalin Zhang. Reassessment of the moth genus Bacotoma, with a new species from Hainan Island Lepidoptera: Crambidae: Spilomelinae ). Insect Systematics \& Evolution, 51(3): 384-407.

Australia, Burma, China, India, Indonesia, Malaysia, Papua New Guinea, Singapore, Sri Lanka, Thailand

Tetracona Jie \& Li [New Genus]

Lu-Lan Jie, Jing-Bo Yang, Wei-Chun Li. First record of the genus Tetracona Meyrick (Lepidoptera, Crambidae) from China, with description of a new species. ZooKeys, 941: 101-105.

CHINA (Jiangxi)

Tetracona multispina Jie \& Li [New Species]

Lu-Lan Jie, Jing-Bo Yang, Wei-Chun Li. First record of the genus Tetracona Meyrick (Lepidoptera, Crambidae) from China, with description of a new species. ZooKeys, 941: 101-105.

CHINA (Jiangxi)

\section{Coleophoridae 鞘蛾科}

Goniodoma auroguttella Zeller, 1849 [New Record]

Jiaqi Deng, Kang Lou, Houhun Li. The genus Goniodoma Zeller (Lepidoptera: Coleophoridae) from China. Entomotaxonomia, 42(4): 258-264.

CHINA (Ningxia)

\section{Depressariidae 宽蛾科}

Agonopterix bipunctifera (Matsumura, 1931) [New Record]

Houhong Li, Shuxia Wang, Mujie Qi. Fauna of Tianmu Mountain Volume X: 94.

CHINA (Zhejiang, Tianjin, Jiangxi, Henan, Hubei); Korea, Japan.

Agonopterix l-nigrum (Matsumura, 1931) [New Record]

Houhong Li, Shuxia Wang, Mujie Qi. Fauna of Tianmu Mountain Volume X: 95.

CHINA (Heilongjiang, Henan), Japan

Ethmia lunaris S. Wang [New Species]

\section{Ethmiidae 草蛾科}

Houhong Li, Shuxia Wang, Mujie Qi. Fauna of Tianmu Mountain Volume X: 102.

CHINA (Zhejiang, Henan)

\section{Erebidae 目夜蛾科}

Aberrasine lichenshihi Wu \& Kishida [New Species]

Shipher Wu \& Y. Kishida Descriptions of three new species of the Miltochrista generic complex in Taiwan (Lepidoptera: Erebidae: Arctiinae). Japan Heterocerists’ J., 293: 450-456.

CHINA (Taiwan)

Aberrasine shiou (Wu \& Kishida, 2020) [New combination]

A.V. Volynkin Re-characterization of two Lithosiini species recently described from the island of Taiwan, with establishing of a new combination and the corrected checklist of the genus Aberrasine Volynkin \& Huang, 2019 (Lepidoptera: Erebidae: Arctiinae: Lithosiini). Ecologica Montenegrina, 38: 119-126.

CHINA (Taiwan)

Ammatho (Delineatia) tairadiata Wu \& Volynkin [New Species]

Anton V. Volynkin, Shipher Wu. A review of the subgenus Delineatia Volynkin \& Huang, 2019 of the genus Ammatho Walker, 1855, with descriptions of two new species from Taiwan and Vietnam (Lepidoptera, Erebidae, Arctiinae, Lithosiini). Zootaxa, 4801 (2): $237-$ 250.

CHINA (Taiwan)

Ammatho (Striatella) inexpecta Huang \& Volynkin [New Species]

Si-Yao Huang, Anton V. Volynkin, Min Wang \& Xiao-Ling Fan. Three new species of the genus Ammatho Walker, 1855 from China and Indochina (Lepidoptera: Erebidae: Arctiinae: Lithosiini). Zootaxa, 4809(3): 582-592.

CHINA (Guangdong), Vietnam 
Ammatho (Ammathella) gesar Huang \& Volynkin [New Species]

Si-Yao Huang, Anton V. Volynkin, Min Wang \& Xiao-Ling Fan. Three new species of the genus Ammatho Walker, 1855 from China and Indochina (Lepidoptera: Erebidae: Arctiinae: Lithosiini). Zootaxa, 4809(3): 582-592.

CHINA (Xizang)

Ammatho (Ammathella) shingwa Volynkin \& Huang [New Species]

Si-Yao Huang, Anton V. Volynkin, Min Wang \& Xiao-Ling Fan. Three new species of the genus Ammatho Walker, 1855 from China and Indochina (Lepidoptera: Erebidae: Arctiinae: Lithosiini). Zootaxa, 4809(3): 582-592.

CHINA (Vietnam)

Ammatho shiou Wu \& Kishida [New Species]

Shipher Wu \& Y. Kishida Descriptions of three new species of the Miltochrista generic complex in Taiwan (Lepidoptera: Erebidae: Arctiinae). Japan Heterocerists' J., 293: 450-456.

CHINA (Taiwan)

Araeopteron canescens (Walker) [New Record]

Jun Wu, Ting-Ting Zhao \& Hui-Lin Han Two new records species of the genus Araeopteron (Erebidae: Boletobiinae: Araeopteronini) from China. Journal of Northeast Forestry University, 48(5): 144-147.

CHINA (Hainan, Yunnan)

Araeopteron fasciale (Hampson) [New Record]

Jun Wu, Ting-Ting Zhao \& Hui-Lin Han Two new records species of the genus Araeopteron (Erebidae: Boletobiinae: Araeopteronini) from China. Journal of Northeast Forestry University, 48(5): 144-147.

CHINA (Hunan, Guangdong, Guizhou)

Asuridia nigrubra Huang, Volynkin \& Wang [New Species]

Si-Yao Huang, Anton V. Volynkin, Min Wang, Xiao-Ling Fan. A remarkable new species of Asuridia Hampson, 1900 from China (Lepidoptera: Erebidae: Arctiinae: Lithosiini). Zootaxa, 4816(2): 217-222.

CHINA (Hubei)

Barsine tongi Huang \& Volynkin [New Species]

Si-Yao Huang, Anton V. Volynkin, Min Wang, Xiao-Ling Fan. Taxonomic problems surrounding Barsine orientalis bigamica Cerny \& Pinratana, 2009 with description of a new species (Lepidoptera, Erebidae, Arctiinae, Lithosiini). Zootaxa, 4894 (4): 549-560.

CHINA (Hainan)

Barsine kampoli Černý in Černý \& Pinratana, 2009 [New Synomyms]

S.: Barsine bigamica Černý \& Pinratana, 2009

Si-Yao Huang, Anton V. Volynkin, Min Wang, Xiao-Ling Fan. Taxonomic problems surrounding Barsine orientalis bigamica Cerny \& Pinratana, 2009 with description of a new species (Lepidoptera, Erebidae, Arctiinae, Lithosiini). Zootaxa, 4894 (4): $549-560$.

CHINA (Yunnan)

Barsine bigamica Černý \& Pinratana, 2009 [New ranking]

Si-Yao Huang, Anton V. Volynkin, Min Wang, Xiao-Ling Fan. Taxonomic problems surrounding Barsine orientalis bigamica Cerny \& Pinratana, 2009 with description of a new species (Lepidoptera, Erebidae, Arctiinae, Lithosiini). Zootaxa, 4894 (4): 549-560.

CHINA (Yunnan)

Cyana barbora Volynkin \& Saldaitis [New Species]

A.V. Volynkin \& A. Saldaitis Cyana barbora, a new species from Sichuan, southwestern China (Lepidoptera, Erebidae, Arctiinae, Lithosiini). Zootaxa, 4885(4): 596-599.

CHINA (Sichuan)

Diduga albicosta Hampson [New Record]

Ulziijargal Bayarsaikhan, Houhun Li, Kyung-Hoan Im, Yang-Seop Bae. Four new and three newly recorded species of Diduga Moore, [1887] (Lepidoptera, Erebidae, Arctiinae) from China. Zootaxa, 4751(2): 357-368.

CHINA (Yunnan)

Diduga allodubatolovi Bayarsaikhan, Li \& Bae [New Species]

Ulziijargal Bayarsaikhan, Houhun Li, Kyung-Hoan Im, Yang-Seop Bae. Four new and three newly recorded species of Diduga Moore, [1887] (Lepidoptera, Erebidae, Arctiinae) from China. Zootaxa, 4751(2): 357-368.

CHINA (Yunnan)

Diduga chebalinga Zhao \& Han [New Species]

Ting Ting Zhao, Hui Lin Han. Four new species of the genus Diduga Moore, [1887] (Lepidoptera, Erebidae, Arctiinae) from China and Malaysia. ZooKeys, 985: 127-141

CHINA (Guangdong) 
Diduga hainanensis Bayarsaikhan, Li \& Bae [New Species]

Ulziijargal Bayarsaikhan, Houhun Li, Kyung-Hoan Im, Yang-Seop Bae. Four new and three newly recorded species of Diduga Moore, [1887] (Lepidoptera, Erebidae, Arctiinae) from China. Zootaxa, 4751 (2): 357-368.

CHINA (Hainan)

Diduga hanoiensis Bayarsaikhan \& Bae [New Record]

Ulziijargal Bayarsaikhan, Houhun Li, Kyung-Hoan Im, Yang-Seop Bae Four new and three newly recorded species of Diduga Moore, [1887] (Lepidoptera, Erebidae, Arctiinae) from China. Zootaxa, 4751 (2): 357-368.

CHINA (Hainan, Guizhou)

Diduga luteogibbosa Bayarsaikhan, Li \& Bae [New Species]

Ulziijargal Bayarsaikhan, Houhun Li, Kyung-Hoan Im, Yang-Seop Bae. Four new and three newly recorded species of Diduga Moore, [1887] (Lepidoptera, Erebidae, Arctiinae) from China. Zootaxa, 4751 (2): 357-368.

CHINA (Yunnan)

Diduga nigridentata Bayarsaikhan \& Bae [New Record]

Ulziijargal Bayarsaikhan, Houhun Li, Kyung-Hoan Im, Yang-Seop Bae. Four new and three newly recorded species of Diduga Moore, [1887] (Lepidoptera, Erebidae, Arctiinae) from China. Zootaxa, 4751 (2): 357-368.

CHINA (Hainan, Guangxi, Guizhou)

Diduga scalprata Bayarsaikhan, Li \& Bae [New Species]

Ulziijargal Bayarsaikhan, Houhun Li, Kyung-Hoan Im, Yang-Seop Bae. Four new and three newly recorded species of Diduga Moore, [1887] (Lepidoptera, Erebidae, Arctiinae) from China. Zootaxa, 4751 (2): 357-368.

CHINA (Yunnan)

Diduga simianshana Zhao \& Han [New Species]

Ting Ting Zhao, Hui Lin Han. Four new species of the genus Diduga Moore, [1887] (Lepidoptera, Erebidae, Arctiinae) from China and Malaysia. ZooKeys, 985: 127-141.

CHINA (Chongqing)

Gandhara jieenchenae Chen \& Wu [New Species]

Ding-Jia Chen \& Shipher Wu. Description of a new Gandhara Moore, 1878 species of Taiwan (Erebidae, Arctiinae, Lithosiine). Japan Heterocerists' J., 294: 482-484.

CHINA (Taiwan)

Huangilene alikangiae Volynkin \& Černý [New Species]

A.V. Volynkin \& K. Černý Huangilene, a new genus for the Miltochrista alikangiae (Strand, 1917) species-group, with descriptions of three new species from Indochina, continental China and Taiwan (Lepidoptera: Erebidae: Arctiinae: Lithosiini). Zootaxa, 4869(1): 091-111.

CHINA (Taiwan)

Huangilene kutzscheri Volynkin \& Černý [New Species]

A.V. Volynkin \& K. Černý Huangilene, a new genus for the Miltochrista alikangiae (Strand, 1917) species-group, with descriptions of three new species from Indochina, continental China and Taiwan (Lepidoptera: Erebidae: Arctiinae: Lithosiini). Zootaxa, 4869(1): 091-111.

CHINA (Fujian)

Lemyra (Thyrgorina) persephone Saldaitis, Volynkin \& Dubatolov [New Species]

A. Saldaitis, A.V. Volynkin \& V.V. Dubatolov Lemyra persephone, a new autumnal species from Yunnan, southwestern China (Lepidoptera, Erebidae, Arctiinae). Zootaxa, 4768 (3): 446-450.

CHINA (Yunnan)

Miltochrista adelfika Volynkin, N. Singh, Černý, Kirti \& Datta [New Species]

A.V. Volynkin, N. Singh, K. Černý, J.S. Kirti \& H.S. Datta Revision of the Miltochrista obliquilinea species-group, with descriptions of four new species (Lepidoptera, Erebidae, Arctiinae, Lithosiini). Zootaxa, 4780 (3): 448-470.

CHINA (Yunnan)

Miltochrista yueh Wu \& Kishida [New Species]

Shipher Wu \& Y. Kishida Descriptions of three new species of the Miltochrista generic complex in Taiwan (Lepidoptera: Erebidae: Arctiinae). Japan Heterocerists' J., 293: 450-456.

CHINA (Taiwan)

Parabitecta secunda Volynkin \& Saldaitis [New Species]

A.V. Volynkin \& A. Saldaitis A new species of the genus Parabitecta Hering, 1926 from Northern Vietnam and Southwestern China, with notes on the taxonomy of the genus Manulea Wallengren, 1872 (Lepidoptera: Erebidae: Arctiinae: Lithosiini). Ecologica Montenegrina, 38: 107-113. 


\section{CHINA (Sichuan)}

Stigmatophora cernyi Volynkin [New Species]

A.V. Volynkin On the taxonomy of the genera Stigmatophora Staudinger, 1881 and Miltochrista Hübner, [1819], with description of a new species from North Thailand and China (Lepidoptera, Erebidae, Arctiinae, Lithosiini). Zootaxa, 4789(2): 508-522.

CHINA (Southwest)

\section{Gelechiidae 麦蛾科}

Anarsia silvosa Ueda, 1997 [New Record]

Houhong Li, Shuxia Wang, Mujie Qi. Fauna of Tianmu Mountain Volume X: 129.

CHINA (Zhejiang, Anhui, Hubei), Japan.

Dichomeris argentenigera Li, Zhen \& Kendrick, 2010 [New Record]

Kyu-Tek Park, Yang-Seop Bae, Shengnan Zhao, Houhun Li. Thirteen new species of genera Dichomeris Hübner, 1818 and Helcystogramma Zeller, 1877 (Lepidoptera, Gelechiidae, Dichomeridinae) with twenty-one newly recorded species from Vietnam. Zootaxa, 4821 (3): 435-461.

VIETNAM, China

Dichomeris crambaleas (Meyrick, 1913) [New Record]

Kyu-Tek Park, Yang-Seop Bae, Shengnan Zhao, Houhun Li. Thirteen new species of genera Dichomeris Hübner, 1818 and Helcystogramma Zeller, 1877 (Lepidoptera, Gelechiidae, Dichomeridinae) with twenty-one newly recorded species from Vietnam. Zootaxa, 4821 (3): 435-461.

VIETNAM, China, India

Dichomeris ferrogra Li \& Wang, 1997 [New Record]

Kyu-Tek Park, Yang-Seop Bae, Shengnan Zhao, Houhun Li. Thirteen new species of genera Dichomeris Hübner, 1818 and Helcystogramma Zeller, 1877 (Lepidoptera, Gelechiidae, Dichomeridinae) with twenty-one newly recorded species from Vietnam. Zootaxa, 4821 (3): 435-461.

VIETNAM, China, Thailand

Dichomeris ferruginosa Meyrick, 1913 [New Record]

Kyu-Tek Park, Yang-Seop Bae, Shengnan Zhao, Houhun Li. Thirteen new species of genera Dichomeris Hübner, 1818 and Helcystogramma Zeller, 1877 (Lepidoptera, Gelechiidae, Dichomeridinae) with twenty-one newly recorded species from Vietnam. Zootaxa, 4821 (3): 435-461.

VIETNAM, China, Japan, Indonesia, India

Dichomeris foliforma Li \& Park [New Record]

Kyu-Tek Park, Yang-Seop Bae, Shengnan Zhao, Houhun Li. Thirteen new species of genera Dichomeris Hübner, 1818 and Helcystogramma Zeller, 1877 (Lepidoptera, Gelechiidae, Dichomeridinae) with twenty-one newly recorded species from Vietnam. Zootaxa, 4821 (3): 435-461.

VIETNAM, China, Cambodia

Dichomeris fuscusitis Li \& Zheng [New Record]

Kyu-Tek Park, Yang-Seop Bae, Shengnan Zhao, Houhun Li. Thirteen new species of genera Dichomeris Hübner, 1818 and Helcystogramma Zeller, 1877 (Lepidoptera, Gelechiidae, Dichomeridinae) with twenty-one newly recorded species from Vietnam. Zootaxa, 4821 (3): 435-461.

VIETNAM, China

Dichomeris hainanensis Li \& Park [New Record]

Kyu-Tek Park, Yang-Seop Bae, Shengnan Zhao, Houhun Li. Thirteen new species of genera Dichomeris Hübner, 1818 and Helcystogramma Zeller, 1877 (Lepidoptera, Gelechiidae, Dichomeridinae) with twenty-one newly recorded species from Vietnam. Zootaxa, 4821 (3): 435-461.

VIETNAM, China, Cambodia

Dichomeris infundibularis Park \& Li [New Species]

Kyu-Tek Park, Yang-Seop Bae, Shengnan Zhao, Houhun Li. Thirteen new species of genera Dichomeris Hübner, 1818 and Helcystogramma Zeller, 1877 (Lepidoptera, Gelechiidae, Dichomeridinae) with twenty-one newly recorded species from Vietnam. Zootaxa, 4821 (3): 435-461.

\section{CHINA, VIETNAM}

Dichomeris malacodes (Meyrick, 1910) [New Record]

Kyu-Tek Park, Yang-Seop Bae, Shengnan Zhao, Houhun Li. Thirteen new species of genera Dichomeris Hübner, 1818 and Helcystogramma Zeller, 1877 (Lepidoptera, Gelechiidae, Dichomeridinae) with twenty-one newly recorded species from Vietnam. Zootaxa, 4821 (3): 435-461.

VIETNAM, China, India, Sri lanka, Indonesia 
Dichomeris meridionalis Li [New Record]

Kyu-Tek Park, Yang-Seop Bae, Shengnan Zhao, Houhun Li. Thirteen new species of genera Dichomeris Hübner, 1818 and Helcystogramma Zeller, 1877 (Lepidoptera, Gelechiidae, Dichomeridinae) with twenty-one newly recorded species from Vietnam. Zootaxa, 4821 (3): 435-461.

VIETNAM, China

Dichomeris orientis Park \& Hodges [New Record]

Kyu-Tek Park, Yang-Seop Bae, Shengnan Zhao, Houhun Li. Thirteen new species of genera Dichomeris Hübner, 1818 and Helcystogramma Zeller, 1877 (Lepidoptera, Gelechiidae, Dichomeridinae) with twenty-one newly recorded species from Vietnam. Zootaxa, 4821 (3): 435-461.

VIETNAM, Cambodia, China

Dichomeris parvisexafurca Li, Zhen \& Kendrick, 2010 [New Record]

Kyu-Tek Park, Yang-Seop Bae, Shengnan Zhao, Houhun Li. Thirteen new species of genera Dichomeris Hübner, 1818 and Helcystogramma Zeller, 1877 (Lepidoptera, Gelechiidae, Dichomeridinae) with twenty-one newly recorded species from Vietnam. Zootaxa, 4821 (3): 435-461.

VIETNAM, China

Dichomeris polygona Li \& Zheng, 1996 [New Record]

Kyu-Tek Park, Yang-Seop Bae, Shengnan Zhao, Houhun Li. Thirteen new species of genera Dichomeris Hübner, 1818 and Helcystogramma Zeller, 1877 (Lepidoptera, Gelechiidae, Dichomeridinae) with twenty-one newly recorded species from Vietnam. Zootaxa, 4821 (3): 435-461.

VIETNAM, China

Dichomeris quadrifurca Li \& Zheng [New Record]

Kyu-Tek Park, Yang-Seop Bae, Shengnan Zhao, Houhun Li. Thirteen new species of genera Dichomeris Hübner, 1818 and Helcystogramma Zeller, 1877 (Lepidoptera, Gelechiidae, Dichomeridinae) with twenty-one newly recorded species from Vietnam. Zootaxa, 4821 (3): 435-461.

VIETNAM, China

Dichomeris sexafurca Li \& Zheng, [New Record]

Kyu-Tek Park, Yang-Seop Bae, Shengnan Zhao, Houhun Li. Thirteen new species of genera Dichomeris Hübner, 1818 and Helcystogramma Zeller, 1877 (Lepidoptera, Gelechiidae, Dichomeridinae) with twenty-one newly recorded species from Vietnam. Zootaxa, 4821 (3): 435-461.

VIETNAM, China

Dichomeris splendiptera Li \& Park [New Record]

Kyu-Tek Park, Yang-Seop Bae, Shengnan Zhao, Houhun Li. Thirteen new species of genera Dichomeris Hübner, 1818 and Helcystogramma Zeller, 1877 (Lepidoptera, Gelechiidae, Dichomeridinae) with twenty-one newly recorded species from Vietnam. Zootaxa, 4821 (3): 435-461.

VIETNAM, Cambodia, China

Dichomeris spinosella Park \& Li [New Species]

Kyu-Tek Park, Yang-Seop Bae, Shengnan Zhao, Houhun Li. Thirteen new species of genera Dichomeris Hübner, 1818 and Helcystogramma Zeller, 1877 (Lepidoptera, Gelechiidae, Dichomeridinae) with twenty-one newly recorded species from Vietnam. Zootaxa, 4821 (3): 435-461.

CHINA, VIETNAM

Dichomeris summata Meyrick, 1913 [New Record]

Kyu-Tek Park, Yang-Seop Bae, Shengnan Zhao, Houhun Li. Thirteen new species of genera Dichomeris Hübner, 1818 and Helcystogramma Zeller, 1877 (Lepidoptera, Gelechiidae, Dichomeridinae) with twenty-one newly recorded species from Vietnam. Zootaxa, 4821 (3): 435-461.

VIETNAM, India, China

Helcystogramma imagitrijunctum Li \& Zhen [New Record]

Kyu-Tek Park, Yang-Seop Bae, Shengnan Zhao, Houhun Li. Thirteen new species of genera Dichomeris Hübner, 1818 and Helcystogramma Zeller, 1877 (Lepidoptera, Gelechiidae, Dichomeridinae) with twenty-one newly recorded species from Vietnam. Zootaxa, 4821 (3): 435-461.

VIETNAM, China

Tornodoxa longiella Park, 1993 [New Record]

Houhong Li, Shuxia Wang, Mujie Qi. Fauna of Tianmu Mountain Volume X: 139.

CHINA (Zhejiang, Hubei), Korea, Japan.

\section{Geometridae 尺蛾科}


Xinyi Zhang, Wenkai Wang, Hongxiang Han. A taxonomic study of the genus Antitrygodes (Lepidoptera: Geometridae: Sterrhinae) with two newly recorded species from China. Entomotaxonomia, 42(1): 33-41.

CHINA (Guangxi, Hainan)

Antitrygodes cuneilinea (Walker, 1863) [New Record]

Xinyi Zhang, Wenkai Wang, Hongxiang Han. A taxonomic study of the genus Antitrygodes (Lepidoptera: Geometridae: Sterrhinae) with two newly recorded species from China. Entomotaxonomia, 42(1): 33-41.

CHINA (Yunnan)

Apochima excavata (Dyar, 1905) [New Record]

Wu, Shipher, Fu, Chien-Ming, Tzu, Han-Rong, Shih, Li-Cheng, Chang, Wei-Chun, Cheng, An-Ping, Lai, Chong-Guan, Cherng, Jyh-Jong. Notes on Uncommon and Newly Recorded Geometrid Moths of Taiwan (Lepidoptera: Geometridae). Part 1. Taiwanese Journal of Entomological Studies, 5(2): 18-26.

CHINA (Taiwan)

Apochima praeacutaria (Inoue, 1976) [New Record]

Wu, Shipher, Fu, Chien-Ming, Tzu, Han-Rong, Shih, Li-Cheng, Chang, Wei-Chun, Cheng, An-Ping, Lai, Chong-Guan, Cherng. Jyh-Jong Notes on Uncommon and Newly Recorded Geometrid Moths of Taiwan (Lepidoptera: Geometridae). Part 1. Taiwanese Journal of Entomological Studies, 5(2): 18-26.

CHINA (Taiwan)

Casilda hemirosea Cui, Xue \& Jiang [New Species]

L. Cui, D. Y. Xue, N. Jiang. Two new species of the tribe Rhodometrini Agenjo, 1951 from Sichuan, China (Lepidoptera: Geometridae) SHILAP-REVISTA DE LEPIDOPTEROLOGIA 卷: 48 期: 189 页: 167-172

CHINA (Sichuan)

Eilicrinia nuptaria Bremer, 1864 [New Record]

Shipher Wu, Chien-Ming Fu, Han-Rong Tzu, Li-Cheng Shih, Wei-Chun Chang, An-Ping Cheng, Chong-Guan Lai, Jyh-Jong Cherng. Notes on Uncommon and Newly Recorded Geometrid Moths of Taiwan (Lepidoptera: Geometridae). Part 1. Taiwanese Journal of Entomological Studies, 5(2): 18-26.

CHINA (Taiwan)

Eucyclodes infracta (Wileman, 1911) [New Record]

Shipher Wu, Chien-Ming Fu, Han-Rong Tzu, Li-Cheng Shih, Wei-Chun Chang, An-Ping Cheng, Chong-Guan Lai, Jyh-Jong Cherng. Notes on Uncommon and Newly Recorded Geometrid Moths of Taiwan (Lepidoptera: Geometridae). Part 1. Taiwanese Journal of Entomological Studies, 5(2): 18-26.

CHINA (Taiwan)

Hypomecis hyposticta (Wehrli, 1925) [New Record]

Shipher Wu, Chien-Ming Fu, Han-Rong Tzu, Li-Cheng Shih, Wei-Chun Chang, An-Ping Cheng, Chong-Guan Lai, Jyh-Jong Cherng. Notes on Uncommon and Newly Recorded Geometrid Moths of Taiwan (Lepidoptera: Geometridae). Part 1. Taiwanese Journal of Entomological Studies, 5(2): 18-26.

CHINA (Taiwan)

Megabiston plumosaria (Leech, 1891) [New Record]

Shipher Wu, Chien-Ming Fu, Han-Rong Tzu, Li-Cheng Shih, Wei-Chun Chang, An-Ping Cheng, Chong-Guan Lai, Jyh-Jong Cherng. Notes on Uncommon and Newly Recorded Geometrid Moths of Taiwan (Lepidoptera: Geometridae). Part 1. Taiwanese Journal of Entomological Studies, 5(2): 18-26.

CHINA (Taiwan)

Planociampa chlora Yazaki \& Wang, 2003 [New Record]

Shipher Wu, Chien-Ming Fu, Han-Rong Tzu, Li-Cheng Shih, Wei-Chun Chang, An-Ping Cheng, Chong-Guan Lai, Jyh-Jong Cherng. Notes on Uncommon and Newly Recorded Geometrid Moths of Taiwan (Lepidoptera: Geometridae). Part 1 Taiwanese Journal of Entomological Studies, 5 (2): 18-26.

CHINA (Taiwan)

Rhodometra rosea Cui, Xue \& Jiang [New Species]

L. Cui, D. Y. Xue, N. Jiang. Two new species of the tribe Rhodometrini Agenjo, 1951 from Sichuan, China (Lepidoptera: Geometridae) SHILAP-REVISTA DE LEPIDOPTEROLOGIA 卷: 48 期: 189 页: 167-172

CHINA (Sichuan)

Sarcinodes hainana Yu \& Wang [New Species]

Tiantian Yu, Min Wang. A new species of the genus Sarcinodes Guenee, [1858] (Lepidoptera, Geometridae) from China. Zootaxa, 4779(4): 553-562.

CHINA (Hainan)

Sarcinodes lilacina Moore, 1888 [New Record] 
Tiantian Yu, Min Wang. A new species of the genus Sarcinodes Guenee, [1858] (Lepidoptera, Geometridae) from China. Zootaxa, 4779(4): 553-562.

CHINA (Yunnan)

Timandra majuscula Cheng \& Jiang [New Species]

Rui Cheng, Nan Jiang. Two new species of the genus Timandra Duponchel (Lepidoptera: Geometridae) from China. Entomotaxonomia, 42(3): 189-193.

CHINA (Sichuan)

Timandra orhanti Cheng \& Jiang [New Species]

Rui Cheng, Nan Jiang. Two new species of the genus Timandra Duponchel (Lepidoptera: Geometridae) from China. Entomotaxonomia, 42(3): 189-193.

CHINA (Shaanxi)

Timandromorpha enervata Inoue, 1944 [New Record]

Shipher Wu, Chien-Ming Fu, Han-Rong Tzu, Li-Cheng Shih, Wei-Chun Chang, An-Ping Cheng, Chong-Guan Lai, Jyh-Jong Cherng. Notes on Uncommon and Newly Recorded Geometrid Moths of Taiwan (Lepidoptera: Geometridae). Part 1. Taiwanese Journal of Entomological Studies, 5 (2): 18-26.

CHINA (Taiwan)

Xyloscia dentifera Inoue, 1986 [New Record]

Shipher Wu, Chien-Ming Fu, Han-Rong Tzu, Li-Cheng Shih, Wei-Chun Chang, An-Ping Cheng, Chong-Guan Lai, Jyh-Jong Cherng. Notes on Uncommon and Newly Recorded Geometrid Moths of Taiwan (Lepidoptera: Geometridae). Part 1. Taiwanese Journal of Entomological Studies, 5 (2): 18-26.

CHINA (Taiwan)

\section{Hesperiidae 弄蝶科}

Celaenorrhinus pyrrha de Nicéville [New Record]

Guo-Xi Xue, Yutaka Inayoshi, Meng Li, Fu-Ming Zhang, Da-Kun Lai, Hai-Ying Tian. New records of Celaenorrhinus pyrrha de Niceville, 1889 and C. munda (Moore, 1884) from China (Lepidoptera, Hesperiidae). ZooKeys, 985: 61-70

CHINA (Yunnan)

Celaenorrhinus munda munda (Moore, 1884) [New Record]

Guo-Xi Xue, Yutaka Inayoshi, Meng Li, Fu-Ming Zhang, Da-Kun Lai, Hai-Ying Tian. New records of Celaenorrhinus pyrrha de Niceville, 1889 and C. munda (Moore, 1884) from China (Lepidoptera, Hesperiidae). ZooKeys, 985: 61-70

CHINA (Xizang)

Choaspes subcaudatus (C. \& R. Felder, 1867) [New Record]

Huihong Zhang, Jianqing Zhu, Ruihang Dong, Yisong Yue, Shaoji, Hu. New Records of Butterflies from China (Lepidoptera: Rhopalocera): Two Genera and Seven Species. Sichuan Journal of Zoology, 39(2): 214-220.

CHINA (Yunnan)

Ctenoptilum multiguttatum de Nicéville, 1890 [New Record]

Huihong Zhang, Jianqing Zhu, Ruihang Dong, Yisong Yue, Shaoji, Hu. New Records of Butterflies from China (Lepidoptera: Rhopalocera): Two Genera and Seven Species. Sichuan Journal of Zoology, 39(2): 214-220.

CHINA (Yunnan)

Daimio Murray, 1875 [New Synonyms]

S.: Tagiades Hubner, 1819

Zhen-Fu Huang, Hideyuki Chiba, Xiao-Hua Deng, Si-Yao Huang, Min Wang, Xiao-Ling Fan. Molecular and morphological evidence reveals that Daimio Murray, 1875 is a junior synonym of Tagiades Hubner, 1819 (Lepidoptera: Hesperiidae: Tagiadini). Zootaxa, 473 (4): 595-600.

CHINA (Heilongjiang, Shaanxi, Guangxi, Zhejiang), Japan

Iton de Niceéville, 1895 [New Record Genus]

Huihong Zhang, Jianqing Zhu, Ruihang Dong, Yisong Yue, Shaoji, Hu. New Records of Butterflies from China (Lepidoptera: Rhopalocera): Two Genera and Seven Species. Sichuan Journal of Zoology, 39(2): 214-220.

CHINA (Yunnan)

Iton watsonii ( de Nicéville, 1890) [New Record]

Huihong Zhang, Jianqing Zhu, Ruihang Dong, Yisong Yue, Shaoji, Hu. New Records of Butterflies from China (Lepidoptera: Rhopalocera): Two Genera and Seven Species. Sichuan Journal of Zoology, 39(2): 214-220.

CHINA (Yunnan)

Pedesta rubella (Devyatkin, 1996) [New ranking]

Meng Li, Alexander L. Monastyrkii, Kirill A. Kolesnichenko, Zihao Liu, Guoxi Xue, Jifeng Long, Huaxing Tang. Morphological 
and molecular characters reveal the status of Pedesta rubella (Devyatkin, 1996) stat. n. and P. similissima (Devyatkin, 2002) syn. n.(Lepidoptera, Hesperiidae). Zootaxa, 4743 (2): 217-231.

CHINA, Vietnam

Pedesta similissima (Devyatkin, 2002) [New Synonyms]

S.: Pedesta submacula (Leech, 1890)

Meng Li, Alexander L. Monastyrkii, Kirill A. Kolesnichenko, Zihao Liu, Guoxi Xue, Jifeng Long, Huaxing Tang. Morphological and molecular characters reveal the status of Pedesta rubella (Devyatkin, 1996) stat. n. and P. similissima (Devyatkin, 2002) syn. n.(Lepidoptera, Hesperiidae). Zootaxa, 4743 (2): 217-231.

CHINA (Anhui, Fujian, Chongqing, Guizhou, Guangdong, Shaanxi), Vietnam

Pedesta tali Huang [New Combination]

B.: Pedesta masuriensis cuneomaculata Murayama, 1995

H. Chiba, H. Tsukiyama, JY Liang, SM Wang, ZY Shen, YF Hsu. The types of skippers described by Shu-Iti Murayama (Lepidoptera: Hesperiidae). Zootaxa, 4801 (2): 280-290.

CHINA (Yunnan)

Sovia liuzihaoi Huang \& Fan [New Species]

Si-Yao Huang, Xin-Yue Wang, Xiao-Ling Fan. A new species of the genus Sovia Evans, 1949 from South Central Yunnan, China (Lepidoptera, Hesperiidae). Zootaxa, 4731 (4): 565-573.

CHINA (Yunnan)

Thoressa masoni (Moore, [1879] ) [New Record]

Huihong Zhang, Jianqing Zhu, Ruihang Dong, Yisong Yue, Shaoji Hu. New Records of Butterflies from China (Lepidoptera: Rhopalocera): Two Genera and Seven Species. Sichuan Journal of Zoology, 39(2): 214-220.

CHINA (Yunnan)

Tagiades Tethys (Ménétriés, 1875) [New Combination]

B.: Daimio Tethys Murray, 1875

Zhen-Fu Huang, Hideyuki Chiba, Xiao-Hua Deng, Si-Yao Huang, Min Wang, Xiao-Ling Fan. Molecular and morphological evidence reveals that Daimio Murray, 1875 is a junior synonym of Tagiades Hubner, 1819 (Lepidoptera: Hesperiidae: Tagiadini). Zootaxa, 4731 (4): 595-600

CHINA (Heilongjiang, Shaanxi, Guangxi, Zhejiang), Japan

\section{Lecithoceridae 祝蛾科}

Homaloxestis longicornuta Yu \& Wang [New Species]

Shuai Yu, Shuxia Wang. Three new species of the genus Homaloxestis Meyrick, 1910 (Lepidoptera, Lecithoceridae) from China. Zootaxa, 4767(4): 589-597.

CHINA (Yunnan)

Homaloxestis miscogana Wu, 1997 [First time description of the female]

Shuai Yu, Shuxia Wang. Three new species of the genus Homaloxestis Meyrick, 1910 (Lepidoptera, Lecithoceridae) from China. Zootaxa, 4767(4): 589-597.

CHINA (Shaanxi, Sichuan).

Homaloxestis rotundisigna Yu \& Wang [New Species]

Shuai Yu, Shuxia Wang. Three new species of the genus Homaloxestis Meyrick, 1910 (Lepidoptera, Lecithoceridae) from China. Zootaxa, 4767(4): 589-597.

CHINA (Xizang)

Homaloxestis trapezialis Yu \& Wang [New Species]

Shuai Yu, Shuxia Wang. Three new species of the genus Homaloxestis Meyrick, 1910 (Lepidoptera, Lecithoceridae) from China. Zootaxa, 4767(4): 589-597.

CHINA (Hubei)

Tegenocharis tenbrans Gozmány [New Record]

Houhong Li, Shuxia Wang, Mujie Qi. Fauna of Tianmu Mountain Volume X: 59.

CHINA (Zhejiang, Hubei, Fujian, Guangdong, guangxi, Chongqing, Guizhou, Yunnan), Thailand, Nepal.

\section{Limacodidae 刺蛾科}

Caissa yunnana Jun Wu, Chun-Sheng Wu, Hui-Lin Han [New Species]

Wu, Jun, Wu, Chun-Sheng, Han, Hui-Lin. A new species of the genus Caissa Hering, 1931 from Yunnan, China (Lepidoptera, Limacodidae). ZooKeys, 951: 83-89.

CHINA (Yunnan) 
戚慕杰, 孙浩, 左兴海, 李后魂 (2021) 中国鳞翅目新物种 2020 年度报告. 生物多样性, 29, 1035-1039.

http://www.biodiversity-science.net/CN/10.17520/biods.2021245

Epsteinius Lin, Braby \& Hsu [New Genus]

Yu-Chi Lin, M.F. Braby, Yu-Feng Hsu. A new genus and species of slug caterpillar (Lepidoptera: Limacodidae) from Taiwan.

Zootaxa, 4809 (2): 374-382.

CHINA (Taiwan)

Epsteinius luoi Wu [New Species]

Chunsheng Wu. Four new species of Limacodidae from China (Lepidoptera: Zygaenoidea). Zoological Systematics, 45(4): 316-320.

CHINA (Yunnan)

Epsteinius translucidus Lin [New Species]

Yu-Chi Lin, M.F. Braby, Yu-Feng Hsu. A new genus and species of slug caterpillar (Lepidoptera: Limacodidae) from Taiwan.

Zootaxa, 4809 (2): 374-382.

CHINA (Taiwan)

Aphendala notoseusa Wu [New Species]

Chunsheng Wu. Four new species of Limacodidae from China (Lepidoptera: Zygaenoidea). Zoological Systematics, 45(4): 316-320.

CHINA (Fujian)

Aphendala mina Wu [New Species]

Chunsheng Wu. Four new species of Limacodidae from China (Lepidoptera: Zygaenoidea). Zoological Systematics, 45(4): 316-320.

CHINA (Fujian)

Striogyia acuta Wu [New Species]

Chunsheng Wu. Four new species of Limacodidae from China (Lepidoptera: Zygaenoidea). Zoological Systematics, 45(4): 316-320.

CHINA (Shanxi)

Tanvia Solovyev \& Witt, 2009 [New Record Genus]

Jun Wu, Ting-Ting Zhao, Hui-Lin Han. A newly recorded genus Tanvia Solovyev \& Witt, 2009 from China (Lepidoptera: Limacodidae) Journal of Asia-Pacific Biodiversity

CHINA (Yunnan)

Tanvia zolotuhini Solovyev \& Witt, 2009 [New Record]

Jun Wu, Ting-Ting Zhao, Hui-Lin Han. A newly recorded genus Tanvia Solovyev \& Witt, 2009 from China (Lepidoptera: Limacodidae) Journal of Asia-Pacific Biodiversity

CHINA (Yunnan)

\section{Lycaenidae 灰蝶科}

Dodona dipoea pseudokaterina Xue [New Subspecies]

Guo-Xi Xue, Da-Kun Lai, Ru-Yan Xu. Description of a new subspecies of Dodona dipoea Hewitson, [1866] (Lycaenidae: Riodininae) from SW Chongqing, China. Zootaxa, 4895 (3): 440-444.

CHINA (Chongqing)

Famegana nisa (Wallace, 1866) Hsu, YF [New Combination]

B.: Famegana alsulus alsulus: Common and Waterhouse 1981

Hsu, Yu-Feng. The identity of Alfred Wallace's mysterious butterfly taxon Lycaena nisa solved: Famegana nisa comb. nov., a senior synonym of F. alsulus (Lepidoptera, Lycaenidae, Polyommatinae). ZooKeys, 966: 153-162.

CHINA (Taiwan)

Spindasis syama lamuae Hsu, Yu-Feng, Liang, Jia-Yuan [New Subspecies]

Hsu, Yu-Feng, Liang, Jia-Yuan. On systematic status of Spindasis syama Horsfield, [1829] in Taiwan and the Philippines (Lepidoptera: Lycaenidae: Aphnaeini). Zootaxa, 4763 (4): 485-500.

CHINA (Taiwan)

Spindasis negrita Felder, 1862 [New recovered]

Hsu, Yu-Feng, Liang, Jia-Yuan. On systematic status of Spindasis syama Horsfield, [1829] in Taiwan and the Philippines (Lepidoptera: Lycaenidae: Aphnaeini). Zootaxa, 4763 (4): 485-500.

CHINA, Philppines

Zizera taiwana Sonan, 1938 [New synonym]

Zizeeria alsulus eggletoni Corbet, 1941[New synonym]

S.: Lycaena nisa Wallace, 1866

Hsu, Yu-Feng. The identity of Alfred Wallace's mysterious butterfly taxon Lycaena nisa solved: Famegana nisa comb. nov., a senior synonym of F. alsulus (Lepidoptera, Lycaenidae, Polyommatinae). ZooKeys, 966: 153-162.

CHINA 


\section{Micropterigidae 小翅蛾科}

Vietomartyria maoershana Liao, Hirowatari \& Huang [New Species]

Cheng-Qing Liao, Toshiya Hirowatari, Guo-Hua Huang. Descriptions of two new Vietomartyria species (Lepidoptera, Micropterigidae) from China. European Journal of Taxonomy, 610: 1-14.

CHINA (Guangxi)

Vietomartyria wuyunjiena Liao, Hirowatari \& Huang [New Species]

Cheng-Qing Liao, Toshiya Hirowatari, Guo-Hua Huang. Descriptions of two new Vietomartyria species (Lepidoptera, Micropterigidae) from China. European Journal of Taxonomy, 610: 1-14.

CHINA (Hunan)

Diarsia huilini Gyulai \& Saldaitis [New Species]

\section{Noctuidae 夜蛾科}

P. Gyulai \& A. Saldaitis. Notes on the genus Diarsia with description of a new species from China (Lepidoptera: Noctuidae). Zootaxa, 4810 (2): 395-400.

CHINA (Sichuan)

Donda hunana Han, Behounek \& Kononenko [New Species]

H.L. Han, G. Behounenk, V.S. Kononenko. New species of Donda Moore, 1882 and new data on Pantheinae species. Revision of Pantheinae, contribution XIV (Lepidoptera, Noctuidae: Pantheinae). Zootaxa, 4731(2): 279-286.

CHINA (Hunan)

Euxoa intolerabilis suppressabilis Varga, Ronkay \& Ronkay [New Subspecies]

F. Aulombard, B. Landry, P.L. Curval, G. Ronkay, L. Ronkay \& Z. Varga. The Jacques Plante Noctuidae Collection, Part 1, Noctuinae and Hadeninae: 343 pp.

CHINA (Xizang)

Haderonia albiocellina Varga, Ronkay, Gyulai, Kiss \& Ronkay [New Species]

Z. Varga, G. Ronkay, P. Gyulai, Á. Kiss \& L. Ronkay. Noctuinae III. Poliina. A Taxonomic Atlas of the Eurasian and North African Noctuoidea. Vol. XI: 313 pp.

CHINA (Sichuan)

Haderonia allasiestrina Varga, Ronkay, Gyulai, Kiss \& Ronkay [New Species]

Z. Varga, G. Ronkay, P. Gyulai, Á. Kiss \& L. Ronkay. Noctuinae III. Poliina. A Taxonomic Atlas of the Eurasian and North African Noctuoidea. Vol. XI: 313 pp.

CHINA (Sichuan)

Haderonia lasiofallax Varga, Ronkay, Gyulai, Kiss \& Ronkay [New Species]

Z. Varga, G. Ronkay, P. Gyulai, Á. Kiss \& L. Ronkay. Noctuinae III. Poliina. A Taxonomic Atlas of the Eurasian and North African Noctuoidea. Vol. XI: 313 pp.

CHINA (Sichuan, Qinghai)

Haderonia subgrisea Varga, Ronkay, Gyulai, Kiss \& Ronkay [New Species]

Z. Varga, G. Ronkay, P. Gyulai, Á. Kiss \& L. Ronkay. Noctuinae III. Poliina. A Taxonomic Atlas of the Eurasian and North African Noctuoidea. Vol. XI: 313 pp.

CHINA (Sichuan)

Harutaeographa brumosa Yoshimoto [New Record]

P.R. Shashank, B. Benedek. New records of Noctuid moths (Lepidoptera, Noctuidae) from India, Bhutan and China. J. Insect Biodiversity, 020 (1): 026-034.

CHINA (Yunnan)

Lasionycta hospita A. Bang-Haas, 1912 [New Record]

Huilin Han, Vladimir S. Kononenko. Eleven species of noctuid moths new to China of the boreal faunal complex (Lepidoptera: Noctuidae). Journal of Forestry Research, 31 (4): 1405-1415.

CHINA (Heilongjiang). Russia, Mongolia

Lasionycta skraelingia (Herrich-Schaffer, 1852) [New Record]

Huilin Han, Vladimir S. Kononenko. Eleven species of noctuid moths new to China of the boreal faunal complex (Lepidoptera: Noctuidae). Journal of Forestry Research, 31 (4): 1405-1415.

CHINA (Heilongjiang). Russia, Japan, North Europe, North America

Leucapamea srnkai Gyulai \& Saldaitis [New Species]

P. Gyulai \& A. Saldaitis. Leucapamea srnkai sp. n., a new Apameini species from China (Lepidoptera, Noctuidae). Zootaxa, 4786 (4): 597-600.

CHINA (Sichuan) 
Paramathes evdomo Saldaitis, Volynkin \& Gyulai [New Species]

A. Saldaitis, A.V. Volynkin \& P. Gyulai. Paramathes evdomo, a new species from Sichuan, southwestern China (Lepidoptera, Noctuidae, Noctuinae). Zootaxa, 4790 (2): 397-400.

CHINA (Sichuan)

Polia gigantea continentalis Varga, Ronkay, Gyulai, Kiss \& Ronkay [New Subspecies]

Z. Varga, G. Ronkay, P. Gyulai, Á. Kiss \& L. Ronkay. Noctuinae III. Poliina. A Taxonomic Atlas of the Eurasian and North African Noctuoidea. Vol. XI: 313 pp.

CHINA (Gansu, Shaanxi, Hunan, Sichuan)

Polia gigantea gigantea Varga, Ronkay, Gyulai, Kiss \& Ronkay [New Subspecies]

Z. Varga, G. Ronkay, P. Gyulai, Á. Kiss \& L. Ronkay. Noctuinae III. Poliina. A Taxonomic Atlas of the Eurasian and North African Noctuoidea. Vol. XI: 313 pp.

CHINA (Taiwan)

Polia malchani (Draudt, 1934) [New Record]

Huilin Han, Vladimir S. Kononenko. Eleven species of noctuid moths new to China of the boreal faunal complex (Lepidoptera: Noctuidae). Journal of Forestry Research, 31 (4): 1405-1415.

CHINA (Heilongjiang). Russia, Mongolia, North Korea

Polia vespertilio (Draudt, 1934) [New Record]

Huilin Han, Vladimir S. Kononenko. Eleven species of noctuid moths new to China of the boreal faunal complex (Lepidoptera: Noctuidae). Journal of Forestry Research, 31 (4): 1405-1415.

CHINA (Heilongjiang). Russia, Mongolia, North Korea

Stenoloba herbacea Saldaitis \& Volynkin [New Species]

A. Saldaitis \& A.V. Volynkin Two new Stenoloba Staudinger, 1892 from Yunnan, southwestern China (Lepidoptera, Noctuidae, Bryophilinae). Zootaxa, 4755 (3): 545-552.

CHINA (Yunnan)

Stenoloba pontezi Saldaitis \& Volynkin [New Species]

A. Saldaitis \& A.V. Volynkin. Two new Stenoloba Staudinger, 1892 from Yunnan, southwestern China (Lepidoptera, Noctuidae, Bryophilinae). Zootaxa, 4755 (3): 545-552.

CHINA (Yunnan)

Xestia albuncula (Eversmann, 1851) [New Record]

Huilin Han, Vladimir S. Kononenko. Eleven species of noctuid moths new to China of the boreal faunal complex (Lepidoptera: Noctuidae). Journal of Forestry Research, 31 (4): 1405-1415.

CHINA (Inner Mongolia, Heilongjiang, Jilin). Russia, Mongolia, North Korea, Japan, North America

Xestia kolymae (Herz, 1903) [New Record]

Huilin Han, Vladimir S. Kononenko. Eleven species of noctuid moths new to China of the boreal faunal complex (Lepidoptera: Noctuidae). Journal of Forestry Research, 31 (4): 1405-1415.

CHINA (Heilongjiang). Russia, Mongolia, North America

Xestia penthima (Erschoff, 1870) [New Record]

Huilin Han, Vladimir S. Kononenko. Eleven species of noctuid moths new to China of the boreal faunal complex (Lepidoptera: Noctuidae). Journal of Forestry Research, 31 (4): 1405-1415.

CHINA (Heilongjiang). Russia, Mongolia

Xestia rhaetica (Staudinger, 1871) [New Record]

Huilin Han, Vladimir S. Kononenko. Eleven species of noctuid moths new to China of the boreal faunal complex (Lepidoptera: Noctuidae). Journal of Forestry Research, 31 (4): 1405-1415.

CHINA (Jilin). Russia, Mongolia, North Korea, Europe

Xestia sincera (Herrich-Schaffer, 1851) [New Record]

Huilin Han, Vladimir S. Kononenko. Eleven species of noctuid moths new to China of the boreal faunal complex (Lepidoptera: Noctuidae). Journal of Forestry Research, 31 (4): 1405-1415.

CHINA (Heilongjiang). Russia, Mongolia, North Korea, Japan, Europe

Xestia subgrisea (Staudinger, 1897) [New Record]

Huilin Han, Vladimir S. Kononenko. Eleven species of noctuid moths new to China of the boreal faunal complex (Lepidoptera: Noctuidae). Journal of Forestry Research, 31 (4): 1405-1415.

CHINA (Heilongjiang). Russia 
Evonima tianmuensis $\mathrm{Hu}, \mathrm{Yu} \&$ Huang [New Species]

Yan-Qing Hu, Yong Yu, Zhen-Fu Huang. A review of the genus Evonima Walker, 1865 from China with description of a new species (Lepidoptera, Nolidae, Nolinae). Zootaxa, 4750 (2): 286-292.

CHINA (Zhejiang)

Hampsonola ceciliae László \& Sterling [New Species]

G.M. László \& M. Sterling Illustrated checklist of Nolinae (Lepidoptera, Nolidae) of Hong Kong, China, with description of two new species. Ecologica Montenegrina, 33: 35-58.

CHINA (Hongkong)

Spininola kendricki László \& Sterling [New Species]

G.M. László \& M. Sterling Illustrated checklist of Nolinae (Lepidoptera, Nolidae) of Hong Kong, China, with description of two new species. Ecologica Montenegrina, 33: 35-58.

CHINA (Hongkong)

\section{Notodontidae 舟蛾科}

Niganda donella Schintlmeister, 2007 [New Record]

Zhaohui Pan, Liusheng Chen. Description of New R ecord to China ( Lepidoptera, Notodontidae). Journal of Northeast Forestry University, 48: 11.

CHINA (Yunnan)

\section{Nymphalidae 蛱蝶科}

Harmilla Aurivillius [New Synonyms]

S.: Euriphene Boisduval

N. Wahlberg, J. Maresova, M.-R. Leidys, S. Collins, L.-W. Wu. The phylogenetic positions of Bhagadatta Moore, 1898, Kumothales Overlaet, 1940 and Hamillla Aurivillius, 1892 (Lepidoptera, Nymphalidae, Limenitidinae) based on molecular data. Nota Lepidopterologica, 43: 167-171.

Lethe giancbi Lang \& Das [New Species]

G. N. Das, S.-Y. Lang, N. Singh, K. Chandra. Taxonomic Notes on the jalaurida-subgroup of the genus Lethe (Lepidoptera, Nymphalidae, Satyrinae). Zootaxa, 4789(1): 281-290.

CHINA (Xizang)

Lethe gelduba Fruhstorfer, 1911 [New ranking]

G. N. Das, S.-Y. Lang, N. Singh, K. Chandra. Taxonomic Notes on the jalaurida-subgroup of the genus Lethe (Lepidoptera, Nymphalidae, Satyrinae). Zootaxa, 4789(1): 281-290.

CHINA (Sichuan, Yunnan, Xizang), Bhutan

Lethe gelduba nuolaensis Huang, 2001 [New ranking]

G. N. Das, S.-Y. Lang, N. Singh, K. Chandra. Taxonomic Notes on the jalaurida-subgroup of the genus Lethe (Lepidoptera, Nymphalidae, Satyrinae). Zootaxa, 4789(1): 281-290.

CHINA (Yunnan, Xizang), Bhutan

Lethe houjiangae Lang \& Bozano, 2015 [New ranking]

G. N. Das, S.-Y. Lang, N. Singh, K. Chandra. Taxonomic Notes on the jalaurida-subgroup of the genus Lethe (Lepidoptera, Nymphalidae, Satyrinae). Zootaxa, 4789(1): 281-290.

CHINA (Yunnan)

\section{Oecophoridae 织蛾科}

Lasiochira wuzhishanensis Yin [New Species]

Aihui Yin, Yanpeng Cai. One new species and one newly recorded species of the genus Lasiochira Meyrick, 1931 (Lepidoptera, Oecophoridae) from China. ZooKeys, 918: 143-150.

CHINA (Hainan)

Lasiochira pallidiptera Yin, Wang \& Park [New Record]

Aihui Yin, Yanpeng Cai. One new species and one newly recorded species of the genus Lasiochira Meyrick, 1931 (Lepidoptera, Oecophoridae) from China. ZooKeys, 918: 143-150.

CHINA (Hubei)

P. aculeiformis Wang [New Species]

Shuxia Wang, Chen Liu. Taxonomic study of the genus Promalactis Meyrick, 1908 (Lepidoptera: Oecophoridae) IX. The maculosa species-group, with descriptions of eighteen new species. Zootaxa, 4890 (1): 38-66.

CHINA (Guangxi) 
Promalactis albipectinalis Wang [New Species]

Shuxia Wang \& Chen Liu. Taxonomic study of the genus Promalactis Meyrick, 1908 (Lepidoptera: Oecophoridae). VII. The cornigera species group, with descriptions of six new species. Zootaxa, 4718 (1): 77-86.

CHINA (Yunnan)

P. apicitriangula Wang [New Species]

Shuxia Wang, Chen Liu. Taxonomic study of the genus Promalactis Meyrick, 1908 (Lepidoptera: Oecophoridae) IX. The maculosa species-group, with descriptions of eighteen new species. Zootaxa, 4890 (1): 38-66.

CHINA (Yunnan)

Promalactis bomiensis Wang [New Species]

Shuxia Wang, Chen Liu. Taxonomic study of the genus Promalactis Meyrick, 1908 (Lepidoptera: Oecophoridae) IX. The maculosa species-group, with descriptions of eighteen new species. Zootaxa, 4890 (1): 38-66.

CHINA (Xizang)

Promalactis brevipalpa Wang [New Species]

Shuxia Wang, Chen Liu. Taxonomic study of the genus Promalactis Meyrick, 1908 (Lepidoptera: Oecophoridae) IX. The maculosa species-group, with descriptions of eighteen new species. Zootaxa, 4890 (1): 38-66.

CHINA (Guangdong)

Promalactis coloristigmosa Wang [New Species]

Shuxia Wang, Chen Liu. Taxonomic study of the genus Promalactis Meyrick, 1908 (Lepidoptera: Oecophoridae) IX. The maculosa species-group, with descriptions of eighteen new species. Zootaxa, 4890 (1): 38-66.

CHINA (Yunnan)

Promalactis costispinata Wang \& Liu [New Species]

Shuxia Wang, Chen Liu. Taxonomic study of the genus Promalactis Meyrick, 1908 (Lepidoptera: Oecophoridae) VIII. The densimacularis species group, with descriptions of four new species. Zootaxa, 4748 (1): 78-86.

CHINA (Zhejiang)

Promalactis cruciata Wang [New Species]

Shuxia Wang, Chen Liu. Taxonomic study of the genus Promalactis Meyrick, 1908 (Lepidoptera: Oecophoridae) IX. The maculosa species-group, with descriptions of eighteen new species. Zootaxa, 4890 (1): 38-66.

CHINA (Zhejiang)

Promalactis curvispinosa Wang [New Species]

Shuxia Wang, Chen Liu. Taxonomic study of the genus Promalactis Meyrick, 1908 (Lepidoptera: Oecophoridae) IX. The maculosa species-group, with descriptions of eighteen new species. Zootaxa, 4890 (1): 38-66.

CHINA (Guangxi)

Promalactis fasciserrata Wang [New Species]

Shuxia Wang, Chen Liu. Taxonomic study of the genus Promalactis Meyrick, 1908 (Lepidoptera: Oecophoridae) IX. The maculosa species-group, with descriptions of eighteen new species. Zootaxa, 4890 (1): 38-66.

CHINA (Xizang)

Promalactis flavidilineata Wang [New Species]

Shuxia Wang \& Chen Liu. Taxonomic study of the genus Promalactis Meyrick, 1908 (Lepidoptera: Oecophoridae). VII. The cornigera species group, with descriptions of six new species. Zootaxa, 4718 (1): 77-86.

CHINA (Fujian)

Promalactis grandaedeaga Wang [New Species]

Shuxia Wang, Chen Liu. Taxonomic study of the genus Promalactis Meyrick, 1908 (Lepidoptera: Oecophoridae). VII. The cornigera species group, with descriptions of six new species. Zootaxa, 4718 (1): 77-86.

CHINA (Sichuan)

Promalactis lateridentalis Wang [New Species]

Shuxia Wang, Chen Liu. Taxonomic study of the genus Promalactis Meyrick, 1908 (Lepidoptera: Oecophoridae) IX. The maculosa species-group, with descriptions of eighteen new species. Zootaxa, 4890 (1): 38-66.

CHINA (Yunnan)

Promalactis latignatha Wang [New Species]

Shuxia Wang \& Chen Liu. Taxonomic study of the genus Promalactis Meyrick, 1908 (Lepidoptera: Oecophoridae). VII. The cornigera species group, with descriptions of six new species. Zootaxa, 4718 (1): 77-86.

CHINA (Thailand)

Promalactis latispinata Wang [New Species]

Shuxia Wang, Chen Liu. Taxonomic study of the genus Promalactis Meyrick, 1908 (Lepidoptera: Oecophoridae) IX. The maculosa 
species-group, with descriptions of eighteen new species. Zootaxa, 4890 (1): 38-66.

CHINA (Guizhou)

Promalactis libona Wang [New Species]

Shuxia Wang, Chen Liu. Taxonomic study of the genus Promalactis Meyrick, 1908 (Lepidoptera: Oecophoridae) IX. The maculosa species-group, with descriptions of eighteen new species. Zootaxa, 4890 (1): 38-66.

CHINA (Guiozhou)

Promalactis lonchodes Wang [New Species]

Shuxia Wang, Chen Liu. Taxonomic study of the genus Promalactis Meyrick, 1908 (Lepidoptera: Oecophoridae) IX. The maculosa species-group, with descriptions of eighteen new species. Zootaxa, 4890 (1): 38-66.

CHINA (Guizhou)

Promalactis magnispina Wang [New Species]

Shuxia Wang, Chen Liu. Taxonomic study of the genus Promalactis Meyrick, 1908 (Lepidoptera: Oecophoridae) IX. The maculosa species-group, with descriptions of eighteen new species. Zootaxa, 4890 (1): 38-66.

CHINA (Yunnan)

Promalactis malipoensis Wang [New Species]

Shuxia Wang, Chen Liu. Taxonomic study of the genus Promalactis Meyrick, 1908 (Lepidoptera: Oecophoridae). VII. The cornigera species group, with descriptions of six new species. Zootaxa, 4718 (1): 77-86.

CHINA (Yunnan)

Promalactis medilargissima Wang [New Species]

Shuxia Wang, Chen Liu. Taxonomic study of the genus Promalactis Meyrick, 1908 (Lepidoptera: Oecophoridae) IX. The maculosa species-group, with descriptions of eighteen new species. Zootaxa, 4890 (1): 38-66.

CHINA (Xizang)

Promalactis medimacularis Wang [New Species]

Shuxia Wang, Chen Liu. Taxonomic study of the genus Promalactis Meyrick, 1908 (Lepidoptera: Oecophoridae) IX. The maculosa species-group, with descriptions of eighteen new species. Zootaxa, 4890 (1): 38-66.

CHINA (Yunnan)

Promalactis plicata Wang [New Species]

Shuxia Wang, Chen Liu Taxonomic study of the genus Promalactis Meyrick, 1908 (Lepidoptera: Oecophoridae) IX. The maculosa species-group, with descriptions of eighteen new species. Zootaxa, 4890 (1): 38-66.

CHINA (Zhejiang)

Promalactis ramivalvata Wang [New Species]

Shuxia Wang, Chen Liu. Taxonomic study of the genus Promalactis Meyrick, 1908 (Lepidoptera: Oecophoridae) IX. The maculosa species-group, with descriptions of eighteen new species. Zootaxa, 4890 (1): 38-66.

CHINA (Yunnan)

Promalactis serraticostalis Wang [New Species]

Shuxia Wang, Chen Liu. Taxonomic study of the genus Promalactis Meyrick, 1908 (Lepidoptera: Oecophoridae) IX. The maculosa species-group, with descriptions of eighteen new species. Zootaxa, 4890 (1): 38-66.

CHINA (Zhejiang)

Promalactis simingshana Wang \& Liu [New Species]

Shuxia Wang, Chen Liu. Taxonomic study of the genus Promalactis Meyrick, 1908 (Lepidoptera: Oecophoridae) VIII. The densimacularis species group, with descriptions of four new species. Zootaxa, 4748 (1): 78-86.

CHINA (Zhejiang)

Promalactis trimaculata Wang \& Liu [New Species]

Shuxia Wang, Chen Liu. Taxonomic study of the genus Promalactis Meyrick, 1908 (Lepidoptera: Oecophoridae) VIII. The densimacularis species group, with descriptions of four new species. Zootaxa, 4748 (1): 78-86.

CHINA (Guangdong)

Promalactis voluta Wang [New Species]

Shuxia Wang, Chen Liu. Taxonomic study of the genus Promalactis Meyrick, 1908 (Lepidoptera: Oecophoridae). VII. The cornigera species group, with descriptions of six new species. Zootaxa, 4718 (1): 77-86.

CHINA (Zhejiang)

Promalactis yongjiana Wang \& Liu [New Species]

Shuxia Wang, Chen Liu. Taxonomic study of the genus Promalactis Meyrick, 1908 (Lepidoptera: Oecophoridae) VIII. The densimacularis species group, with descriptions of four new species. Zootaxa, 4748 (1): 78-86.

CHINA (Zhejiang) 


\section{Pyralidae 蛽蛾科}

Dusungwua antennalveata Ren \& Li [New Species]

Yingdang Ren, Linlin Yang, Hongxia Liu, Houhun Li. Taxonomic review of the genus Dusungwua Kemal, Kizildağ \& Koçak, 2020 (Lepidoptera: Pyralidae), with descriptions of six new species and propositions of synonyms. Zootaxa, 4894 (3): 341-365.

CHINA (guizhou)

Dusungwua basinigra Ren \& Li [New Species]

Yingdang Ren, Linlin Yang, Hongxia Liu, Houhun Li. Taxonomic review of the genus Dusungwua Kemal, Kizildağ \& Koçak, 2020 (Lepidoptera: Pyralidae), with descriptions of six new species and propositions of synonyms. Zootaxa, 4894 (3): 341-365.

CHINA (Tianjin)

Dusungwua fascecornuta Ren \& Li [New Species]

Yingdang Ren, Linlin Yang, Hongxia Liu, Houhun Li. Taxonomic review of the genus Dusungwua Kemal, Kizildağ \& Koçak, 2020 (Lepidoptera: Pyralidae), with descriptions of six new species and propositions of synonyms. Zootaxa, 4894 (3): 341-365.

CHINA (Guizhou)

Dusungwua paripalpa Ren \& Li [New Species]

Yingdang Ren, Linlin Yang, Hongxia Liu, Houhun Li. Taxonomic review of the genus Dusungwua Kemal, Kizildağ \& Koçak, 2020 (Lepidoptera: Pyralidae), with descriptions of six new species and propositions of synonyms. Zootaxa, 4894 (3): 341-365.

CHINA (Hunan)

Dusungwua quadrangular (Du, Sung \& Wu, 2005) [First time description of the female]

Yingdang Ren, Linlin Yang, Hongxia Liu, Houhun Li. Taxonomic review of the genus Dusungwua Kemal, Kizildağ \& Koçak, 2020 (Lepidoptera: Pyralidae), with descriptions of six new species and propositions of synonyms. Zootaxa, 4894 (3): 341-365.

CHINA (Anhui, Fujian, Guangdong, Guangxi, Jiangxi, Zhejiang)

Dusungwua similiquadrangula Ren \& Li [New Species]

Yingdang Ren, Linlin Yang, Hongxia Liu, Houhun Li. Taxonomic review of the genus Dusungwua Kemal, Kizildağ \& Koçak, 2020 (Lepidoptera: Pyralidae), with descriptions of six new species and propositions of synonyms. Zootaxa, 4894 (3): 341-365.

CHINA (Yunnan)

Dusungwua strictivinculum Ren \& Li [New Species]

Yingdang Ren, Linlin Yang, Hongxia Liu, Houhun Li. Taxonomic review of the genus Dusungwua Kemal, Kizildağ \& Koçak, 2020 (Lepidoptera: Pyralidae), with descriptions of six new species and propositions of synonyms. Zootaxa, 4894 (3): 341-365.

CHINA (Fujian)

Epicrocis datianensis Liu \& Li [New Species]

Hongxia Liu, Houhun Li. Review of the genus Epicrocis Zeller, 1848 in China (Lepidoptera, Pyralidae), with descriptions of three new species. Zootaxa, 4834(1): 133-144.

CHINA (Hainan)

Epicrocis flabelloformis Liu \& Li [New Species]

Hongxia Liu, Houhun Li. Review of the genus Epicrocis Zeller, 1848 in China (Lepidoptera, Pyralidae), with descriptions of three new species. Zootaxa, 4834(1): 133-144.

CHINA (Hainan)

Epicrocis maculata Liu \& Li [New Species]

Hongxia Liu, Houhun Li. Review of the genus Epicrocis Zeller, 1848 in China (Lepidoptera, Pyralidae), with descriptions of three new species. Zootaxa, 4834(1): 133-144.

CHINA (Hainan)

Epicrocis metallopa (Lower, 1898) [New Record]

Hongxia Liu, Houhun Li. Review of the genus Epicrocis Zeller, 1848 in China (Lepidoptera, Pyralidae), with descriptions of three new species. Zootaxa, 4834(1): 133-144.

CHINA (Fujian, Hainan)

Epicrocis pramaoyensis Bae \& Qi [New Record]

Hongxia Liu, Houhun Li. Review of the genus Epicrocis Zeller, 1848 in China (Lepidoptera, Pyralidae), with descriptions of three new species. Zootaxa, 4834(1): 133-144.

CHINA (Yunnan)

Eurhodope pseudodichromella Yamanaka, 1980 [New Synonyms]

S.: Dusungwua dichromella (Ragonot, 1893)

Yingdang Ren, Linlin Yang, Hongxia Liu, Houhun Li. Taxonomic review of the genus Dusungwua Kemal, Kizildağ \& Koçak, 2020 
(Lepidoptera: Pyralidae), with descriptions of six new species and propositions of synonyms. Zootaxa, 4894 (3): 341-365.

CHINA (Anhui, Beijing, Fujian, Gansu, Guangxi, Guizhou, Hebei, Henan, Hubei, Hunan, Jiangxi, Jilin, Liaoning, Shaanxi, Shandong, Sichuan, Tianjin, Zhejiang), Japan.

Pima acutativalva Qi \& Li [New Species]

Mujie Qi, Xinghai Zuo, Houhun Li. Taxonomic study of genus Peucela Ragonot, 1891 (Lepidoptera, Pyralidae) in China, with descriptions of three new species. ZooKeys, 976: 147-158.

CHINA (Xizang)

Peucela baishanzuensis Qi \& Li [New Species]

Mujie Qi, Xinghai Zuo, Houhun Li. Taxonomic study of genus Peucela Ragonot, 1891 (Lepidoptera, Pyralidae) in China, with descriptions of three new species. ZooKeys, 976: 147-158.

CHINA (Zhejiang)

Peucela nigra Qi \& Li [New Species]

Mujie Qi, Xinghai Zuo, Houhun Li. Taxonomic study of genus Peucela Ragonot, 1891 (Lepidoptera, Pyralidae) in China, with descriptions of three new species. ZooKeys, 976: 147-158.

CHINA (Yunnan)

Peucela olivalis Qi \& Li [New Combination]

B.: Bostra olivalis Caradja, 1927

Mujie Qi, Xinghai Zuo, Houhun Li. Taxonomic study of genus Peucela Ragonot, 1891 (Lepidoptera, Pyralidae) in China, with descriptions of three new species. ZooKeys, 976: 147-158.

CHINA (Fujian, Guangxi, Hainan, Hunan, Sichuan, Yunnan, Zhejiang)

Pima tristriata Yang \& Ren [New Species]

Linlin Yang, Yingdang Ren. A new species of Pima Hulst, 1888 from China (Lepidoptera, Pyralidae, Phycitinae), with a key to Holarctic species. ZooKeys, 975: 111-124.

CHINA (Ningxia)

Sciota hamatella (Roesler, 1975) [New Combination; New Record]

B.: Nephopterix hamatella Roesler

Houhong Li, Shuxia Wang, Mujie Qi. Fauna of Tianmu Mountain Volume X: 277.

CHINA (Zhejiang, Beijing).

Trachycera nipponella Yamanaka, 2000 [New Synonyms]

Trachycera vicinella Yamanaka, 2000 [New Synonyms]

Trachycera yakushimensis Yamanaka, 2000 [New Synonyms]

S.: Dusungwua paradichromella (Yamanaka, 1980)

Yingdang Ren, Linlin Yang, Hongxia Liu, Houhun Li. Taxonomic review of the genus Dusungwua Kemal, Kizildağ \& Koçak, 2020 (Lepidoptera: Pyralidae), with descriptions of six new species and propositions of synonyms. Zootaxa, 4894 (3): 341-365.

CHINA (Anhui, Beijing, Guangdong, Gansu, Guizhou, Henan, Hubei, Shandong, Shaanxi, Sichuan, Tianjin, Yunnan, Zhejiang), Japan.

Vietnamodes adelinae Leraut, 2017 [New Record]

Mujie Qi, Houhun Li. Genus Vietnamodes Leraut, 2017 (Lepidoptera, Pyralidae) new to China, with description of a new species. Zootaxa, 4803(1): 190-196.

CHINA (Guangxi)

Vietnamodes dogueti Leraut, 2017 [New Record]

Mujie Qi, Houhun Li. Genus Vietnamodes Leraut, 2017 (Lepidoptera, Pyralidae) new to China, with description of a new species. Zootaxa, 4803(1): 190-196.

CHINA (Yunnan, Guangxi)

Vietnamodes dogueti Leraut, 2017 [First time description of the female]

Mujie Qi, Houhun Li. Genus Vietnamodes Leraut, 2017 (Lepidoptera, Pyralidae) new to China, with description of a new species. Zootaxa, 4803(1): 190-196.

CHINA (Yunnan, Guangxi)

Vietnamodes unicispina Qi \& Li [New Species]

Mujie Qi, Houhun Li Genus Vietnamodes Leraut, 2017 (Lepidoptera, Pyralidae) new to China, with description of a new species. Zootaxa, 4803(1): 190-196.

CHINA (Guangxi)

\section{Roeslerstammiidae 纤蛾科}

Agriothera elaeocarpophaga Moriuti [New Record]

Meiling Zheng, Mujie Qi, Houhun Li. A study on Roeslerstammiidae (Lepidoptera) in the Insect Collection of Nankai University 
(NKU), with descriptions of three new species. Zootaxa, 4728 (3): 372-380.

CHINA (Guangxi, Hainan, Yunnan)

Agriothera microtricha Zheng, Qi \& Li [New Species]

Meiling Zheng, Mujie Qi, Houhun Li. A study on Roeslerstammiidae (Lepidoptera) in the Insect Collection of Nankai University (NKU), with descriptions of three new species. Zootaxa, 4728 (3): 372-380.

CHINA (Yunnan)

Agriothera quadrativalva Zheng, Qi \& Li [New Species]

Meiling Zheng, Mujie Qi, Houhun Li. A study on Roeslerstammiidae (Lepidoptera) in the Insect Collection of Nankai University (NKU), with descriptions of three new species. Zootaxa, 4728 (3): 372-380.

CHINA (Xizang)

Telethera declivimarginata Zheng, Qi \& Li [New Species]

Meiling Zheng, Mujie Qi, Houhun Li. A study on Roeslerstammiidae (Lepidoptera) in the Insect Collection of Nankai University (NKU), with descriptions of three new species. Zootaxa, 4728 (3): 372-380.

CHINA (Yunnan)

\section{Saturniidae 天虫蛾科}

Saturnia paragrotei (Naumann \& Nssig, 2010) [New Record]

Sixun Ge, Zhuoheng Jiang, Shuai Zhao. Two New Species Records of Saturniidae from China (Lepidoptera: Saturniidae). Sichuan Journal of Zoology, 39 (6): 676-678.

CHINA (Xizang)

Saturnia pinratanai (Pinratana \& Lampe, 1990) [New Record]

Sixun Ge, Zhuoheng Jiang, Shuai Zhao. Two New Species Records of Saturniidae from China (Lepidoptera: Saturniidae). Sichuan Journal of Zoology, 39 (6): 676-678.

CHINA (Yunnan)

\section{Sphingidae 天蛾科}

Acosmeryx omissa Rothschild \& Jordan, 1903 [New Record]

Zhuoheng Jiang, Sixun Ge, Zhenbang Xu. New Records of Four Hawkmoths Species ( Lepidoptera: Sphingidae) from China. Sichuan Journal of Zoology, 39(4): 424-428.

CHINA (Xizang)

Ambulyx canescens (Walker, 1865) [New Record]

Zhuoheng Jiang, Sixun Ge, Zhenbang Xu. New Records of Four Hawkmoths Species ( Lepidoptera: Sphingidae) from China. Sichuan Journal of Zoology, 39(4): 424-428.

CHINA (Yunnan)

Ampelophaga thomasi (Cadiou \& Kitching, 1998) [New Record]

Zhuoheng Jiang, Sixun Ge, Zhenbang Xu. New Records of Four Hawkmoths Species ( Lepidoptera: Sphingidae) from China. Sichuan Journal of Zoology, 39(4): 424-428.

CHINA (Xizang)

Cechetra scotti (Rothschild, 1920) [New Record]

Zhuoheng Jiang, Sixun Ge, Zhenbang Xu. New Records of Four Hawkmoths Species ( Lepidoptera: Sphingidae) from China. Sichuan Journal of Zoology, 39(4): 424-428.

CHINA (Yunnan, Xizang)

Dahira sichuanica Jiang \&Wang [New Species]

Zhuo-Heng Jiang, Cheng-Bin Wang. A new species of the genus Dahira Moore (Lepidoptera: Sphingidae) from Sichuan, China. Zootaxa, 4767(3): 485-491.

CHINA (Sichuan)

Eurypteryx dianae Brechlin, 2006 [First time description of the female]

Zhuo-Heng Jiang, Cheng-Bin Wang. Review of the genus Eurypteryx C. Felder \& R. Felder, 1874 from China, with a first description of the male E. dianae (Lepidoptera: Sphingidae). Zootaxa, 4878 (2): 375-384.

CHINA (Guangxi, Guizhou)

\section{Stathmopodidae 展足蛾科}

Cuprina atayalica Shen \& Hsu [New Species] 
Zong-Yu Shen, Yu-Feng Hsu. The fern-feeding genus Cuprina Sinev, 1988 (Lepidoptera, Stathmopodidae), new for Taiwan, with descriptions of two new species. ZooKeys, 915: 117-126.

CHINA (Taiwan)

Cuprina insolita Hsu \& Shen [New Species]

Zong-Yu Shen, Yu-Feng Hsu. The fern-feeding genus Cuprina Sinev, 1988 (Lepidoptera, Stathmopodidae), new for Taiwan, with descriptions of two new species. ZooKeys, 915: 117-126.

CHINA (Taiwan)

Stathmopoda atrifusca Wang, Guan \& Wang [New Species]

Ailing Wang, Wei Guan, Shuxia Wang. Genus Stathmopoda Herrich-Schaffer, 1853 (Lepidoptera: Stathmopodidae) from China: Descriptions of thirteen new species. Zootaxa, 4838 (3): 358-380.

CHINA (Yunnan)

Stathmopoda cellifaria Wang, Guan \& Wang [New Species]

Ailing Wang, Wei Guan, Shuxia Wang. Genus Stathmopoda Herrich-Schaffer, 1853 (Lepidoptera: Stathmopodidae) from China: Descriptions of thirteen new species. Zootaxa, 4838 (3): 358-380.

CHINA (Fujian)

Stathmopoda cornuta Wang, Guan \& Wang [New Species]

Ailing Wang, Wei Guan, Shuxia Wang. Genus Stathmopoda Herrich-Schaffer, 1853 (Lepidoptera: Stathmopodidae) from China: Descriptions of thirteen new species. Zootaxa, 4838 (3): 358-380.

CHINA (Yunnan)

Stathmopoda digitiprocessa Wang, Guan \& Wang [New Species]

Ailing Wang, Wei Guan, Shuxia Wang. Genus Stathmopoda Herrich-Schaffer, 1853 (Lepidoptera: Stathmopodidae) from China: Descriptions of thirteen new species. Zootaxa, 4838 (3): 358-380.

CHINA (Guangxi)

Stathmopoda dolichantha Wang, Guan \& Wang [New Species]

Ailing Wang, Wei Guan, Shuxia Wang. Genus Stathmopoda Herrich-Schaffer, 1853 (Lepidoptera: Stathmopodidae) from China: Descriptions of thirteen new species. Zootaxa, 4838 (3): 358-380.

CHINA (Guangxi)

Stathmopoda falsistimulata Wang, Guan \& Wang [New Species]

Ailing Wang, Wei Guan, Shuxia Wang. Genus Stathmopoda Herrich-Schaffer, 1853 (Lepidoptera: Stathmopodidae) from China: Descriptions of thirteen new species. Zootaxa, 4838 (3): 358-380.

CHINA (Guangxi)

Stathmopoda guangxiensis Wang, Guan \& Wang [New Species]

Ailing Wang, Wei Guan, Shuxia Wang. Genus Stathmopoda Herrich-Schaffer, 1853 (Lepidoptera: Stathmopodidae) from China: Descriptions of thirteen new species. Zootaxa, 4838 (3): 358-380.

CHINA (Guangxi)

Stathmopoda ingena Wang, Guan \& Wang [New Species]

Ailing Wang, Wei Guan, Shuxia Wang. Genus Stathmopoda Herrich-Schaffer, 1853 (Lepidoptera: Stathmopodidae) from China: Descriptions of thirteen new species. Zootaxa, 4838 (3): 358-380.

CHINA (Yunnan)

Stathmopoda liberata Wang, Guan \& Wang [New Species]

Ailing Wang, Wei Guan, Shuxia Wang. Genus Stathmopoda Herrich-Schaffer, 1853 (Lepidoptera: Stathmopodidae) from China: Descriptions of thirteen new species. Zootaxa, 4838 (3): 358-380.

CHINA (Guizhou)

Stathmopoda purpurata Wang, Guan \& Wang [New Species]

Ailing Wang, Wei Guan, Shuxia Wang. Genus Stathmopoda Herrich-Schaffer, 1853 (Lepidoptera: Stathmopodidae) from China: Descriptions of thirteen new species. Zootaxa, 4838 (3): 358-380.

CHINA (Hainan)

Stathmopoda serrifasciaria Wang, Guan \& Wang [New Species]

Ailing Wang, Wei Guan, Shuxia Wang. Genus Stathmopoda Herrich-Schaffer, 1853 (Lepidoptera: Stathmopodidae) from China: Descriptions of thirteen new species. Zootaxa, 4838 (3): 358-380.

CHINA (Hainan)

Stathmopoda similatridorsalis Wang, Guan \& Wang [New Species]

Ailing Wang, Wei Guan, Shuxia Wang. Genus Stathmopoda Herrich-Schaffer, 1853 (Lepidoptera: Stathmopodidae) from China: Descriptions of thirteen new species. Zootaxa, 4838 (3): 358-380. 
戚慕杰, 孙浩, 左兴海, 李后魂 (2021) 中国鳞翅目新物种 2020 年度报告. 生物多样性, 29, 1035-1039.

http://www.biodiversity-science.net/CN/10.17520/biods.2021245

CHINA (Jiangxi)

Stathmopoda spinicornuta Wang, Guan \& Wang [New Species]

Ailing Wang, Wei Guan, Shuxia Wang. Genus Stathmopoda Herrich-Schaffer, 1853 (Lepidoptera: Stathmopodidae) from China: Descriptions of thirteen new species. Zootaxa, 4838 (3): 358-380.

CHINA (Yunnan)

\section{Thyatiridae 波纹蛾科}

Hiroshia shennongjiaensis Ronkay, Ronkay \& Han, [New Species]

Hong Zheng, Gábor Ronkay, László Ronkay, Hui-Lin Han. Description of a new Hiroshia species (Lepidoptera, Thyatiridae) from Hubei Province, China. ZooKeys, 996: 147-152

CHINA (Hubei)

Nemacerota paizhenensis Da, Ronkay \& Han [New Species]

Wa Da, LÁSzlÓ Ronkay \& Huilin Han. Description a new species of Nemacerota Hampson, [1893] (Lepidoptera: Thyatiridae) from the Xizang Autonomous Region, China. Zootaxa, 4810(2): 389-394.

CHINA (Xizang)

\section{Tineidae 谷蛾科}

Dinica claviformis Li [New Species]

Mengran Xing, Linlin Yang, Houhun Li. Three new species of Dinica Gozmány, 1965 (Lepidoptera: Tineidae) from China. Journal of Insect Biodiversity, 14(2): 34-39.

CHINA (Yunnan)

Dinica apicipuncta Li [New Species]

Mengran Xing, Linlin Yang, Houhun Li. Three new species of Dinica Gozmány, 1965 (Lepidoptera: Tineidae) from China. Journal of Insect Biodiversity, 14(2): 34-39.

CHINA (Guizhou)

Dinica bulbella Li [New Species]

Mengran Xing, Linlin Yang, Houhun Li. Three new species of Dinica Gozmány, 1965 (Lepidoptera: Tineidae) from China. Journal of Insect Biodiversity, 14(2): 34-39.

CHINA (Yunnan)

\section{Tortricidae 卷蛾科}

Olethreutes perexiguana Kuznetzov, 1988 [New Record]

Houhong Li, Shuxia Wang, Mujie Qi. Fauna of Tianmu Mountain Volume X: 226.

CHINA (Zhejiang, Anhui, Fujian, Guangxi, Guizhou), Vietnam 